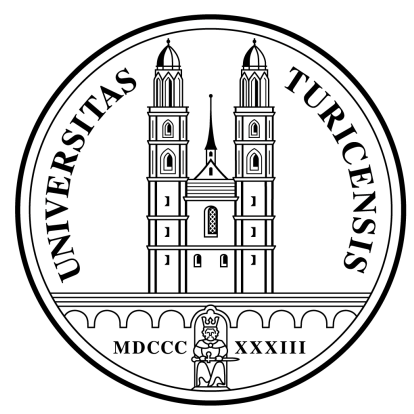

Institute for Empirical Research in Economics

University of Zurich

Working Paper Series

ISSN 1424-0459

Working Paper No. 53

Choosing the Joneses:

On the Endogeneity of Reference Groups

Armin Falk and Markus Knell

July 2000 


\title{
Choosing the Joneses On the Endogeneity of Reference Groups
}

\author{
Armin Falk $^{a}$, Markus Knell ${ }^{a, b, *}$ \\ ${ }^{a}$ Institute for Empirical Economic Research ${ }^{b}$ Austrian National Bank \\ University of Zurich \\ Economic Studies Division \\ Bluemlisalpstrasse 10 \\ Schwarzspanierstrasse 5, POB 61 \\ CH-8006 Zurich \\ A-1011 Vienna, Austria \\ falk@iew.unizh.ch \\ Markus.Knell@oenb.co.at
}

July 26, 2000

\begin{abstract}
A growing economic literature recognizes and deals with the fact that economic agents' utility and well-being is not solely determined by absolute achievements, but also by achievements relative to a reference standard or reference group. In this literature it is assumed that the reference standard is completely exogenous. Social psychologists have questioned the exogenous nature of the comparison process ("forced comparison conception") and have emphasized that people play a more active role in the determination of their reference standards ("coping approach"). The present paper takes up this idea. In our model the reference standard is determined endogenously. Following the social comparison literature we assume that in choosing the optimal reference standard people pursue goals of self-improvement and self-enhancement. Our model predicts that the optimally chosen reference standard (or group) increases in people's abilities. We present new questionnaire data together with a review of various important findings from social perception studies (minimum income, happiness, subjective social class). It turns out that the empirical regularities conform well to the predictions of our model, but are difficult (if not impossible) to explain by both the standard economic approach (with its neglect of social comparison) and the forced comparison approach.
\end{abstract}

JEL: D62, D63, H31, Z13

*We would like to thank Samuel Bowles, Urs Fischbacher, Simon Gächter, Armin Schmutzler and the participants of the research seminar in Zurich. The first author acknowledges support from the MacArthur Foundation (Network on Economic Environments and the Evolution of Individual Preferences and Social Norms). The views expressed in this paper do not necessarily represent the opinion of the Austrian National Bank. 


\section{Introduction}

The idea that economic agents perform social comparison and derive (dis-)utility from these comparisons traces back to the writings of Marx, Durkheim and Veblen. In more recent times Duesenberry (1949), Easterlin $(1974,1995)$ and Frank $(1985,1999)$ have advocated the fact that economic agents' well-being is not solely determined by their absolute performance, but also by their performance relative to others. Frank, e.g., states that "without taking people's concerns about relative standing into account, economists have been led to adopt a variety of theories that seem either utterly implausible as descriptions of human behavior or sharply at variance with observed facts" (Frank, 1985, p. 38).

Taking up this view there are by now various fields of economic research where a concern for relative standing is regarded as an important concept: In labor relations, e.g., it has been shown that workers do not care only about their own wage payments but also about their co-workers' wages. This is why employers are keen to keep the wage structure within their firm stable and to treat workers "fairly" (Akerlof and Yellen (1990), Bewley (1995), Campbell and Camlani (1997), Fehr and Falk (1999)). Similarly, studies on happiness and subjective-well being have come to the conclusion that relative performance crucially determines the perception of people's happiness. Summarizing their empirical investigation, Clark and Oswald (1996), e.g., note that their results "appear to offer statistical credence to the hypothesis that feelings of well-being depend of a reference or comparison level of income. By contrast they provide little support for the simple view, presented in microeconomics textbooks, that a worker's level of well-being is a function of absolute income" (p. 373). Further economic research along these lines includes studies on savings and consumption behavior (Carroll, 1998; Frank 1985), labor supply (Boskin and Sheshinski, 1978; Neumark and Postlewaite, 1998; Kapteyn and Woittiez, 1998), the behavior of financial markets (Campbell and Cochrane, 1999), on inequality and growth (Cooper and Garcia-Penalosa, 1999; Knell, 1999) and fairness (Adams, 1965; Fehr and Schmidt, 1999; Falk and Fischbacher, 1999).

In general, models of relative comparison share three basic features. First, utility is defined not only in terms of an individual's absolute performance, e.g., income $c$, but also in terms of the performance relative to a reference group or reference standard $r$, i.e., $U=U(c, r)$. Second, utility is increasing in the level of $c$ and decreasing in the level of $r$, i.e., $\partial U / \partial c>0$ and $\partial U / \partial r<0$. Third, the reference standard $r$ is assumed to be exogenously given. Moreover, it is often assumed that $r$ is the same for all people in a given environment (e.g., equal to the average consumption level of a particular society). The present paper relaxes the third feature. In particular we assume that individuals have at least some discretion about their reference standard, i.e., $r$ is endogenously determined.

The assumption of an exogenous reference standard rests on the idea that the social environment dictates the comparison standards. People are assumed to be 
completely passive with respect to their reference group. Taking up a distinction made by Diener and Fujita (1997) this type of social comparison can be called a "forced comparison conception" in contrast to the so-called "coping approach". According to the latter concept, people take "a much more active role, consciously selecting comparison targets from a wide array of available others in order to meet varying goals" (p. 330). In our model we take this idea into account: People can (at least partly) choose their reference groups or standards. We show that this not only provides a better understanding of the social comparison process (as discussed in the social psychological literature) but also yields predictions that fit actual behavior better than the models guided by the 'forced comparison conception'.

The paper consists of two parts. In Section 2 we derive a formal social comparison model with endogenous reference standard. The main implication of the model is that the choice of the reference standard (or group) depends on people's abilities. The higher an individual's ability the higher the corresponding reference standard. In Section 3 we present empirical evidence that supports the main predictions of our model. First, we report new data from a questionnaire study we conducted that show that people with higher abilities do in fact choose higher reference standards. Second, we present various important findings from social perception studies (minimum income, happiness, subjective social class). It turns out that the empirical regularities conform well to the predictions of our model, but are difficult (if not impossible) to explain by both the standard economic approach (with its neglect of social comparison) and the forced comparison approach. Section 4 concludes.

\section{Modeling the social comparison process}

\subsection{The basic ideas}

Most of the existing economic literature on social comparison has assumed reference standards to be exogenous (e.g., Boskin and Sheshinski, 1978; Hof, 1999; Easterlin, 1974, 1995). The latter, e.g., assumes that people's modal comparison standard is the average wealth level in a society. As a society gets richer, the comparison target inevitably moves up as well. This exogenous or "forced" comparison conception assumes that comparison standards are imposed by the performance of our (local) social environment.

Contrary to this solely environmentally induced perception of reference standards many social psychologists have emphasized the endogenous nature of the comparison process (e.g., Wood and Taylor 1991). According to the 'coping approach' (Diener and Fujita 1997) people play an active role in determining reference standards, goals and comparison others. This approach stresses the flexibility of people to use social information and it refers to the substantial differences between comparing individuals and the instrumental usage of comparison targets to serve self-relevant goals. In this vein Kruglanski and Mayseless (1990), e.g., note that "referent others with whom 
persons might wish to compare are quite diverse and unconstrained" (p. 204).

Given that people actively engage in selecting comparison targets, the immediate question is: to what end? What are the goals that are pursued in the process of selecting a reference standard? Two of the most important goals studied in the social comparison literature are "self-improvement" and "self-enhancement" (see, e.g., Wood and Taylor, 1991 and the references cited there).

Self-enhancement refers to the fact that comparison with others who are inferior often makes us feel better. For reasons of self-enhancement, people engage in downward comparison (Wills, 1981), i.e., they compare with others who are inferior or less fortunate. Brown and Dutton (1995), e.g., have shown that people make comparisons with others "when they think that it will make them feel good" (p. 1292). By contrasting one's own circumstances with those that are worse off "one may feel less threatened" (Taylor, Wood and Lichtman, 1983). As a consequence, downward comparison is a coping strategy to enhance moods and subjective well-being. This coping strategy has shown to be of particular importance for people who suffer from major medical problems (see Affleck and Tennen, 1991). As a consequence of using downward comparisons people see themselves as highly talented and underestimate others' talents (Campbell 1986, Marks 1984). Summarizing the empirical evidence Wood and Taylor (1991) conclude that " $[\mathrm{w}]$ hen one has an unfavorable characteristic, one may self-enhance by reminding oneself of others who are similarly flawed. Even better is a downward comparison - someone who possesses even more of the undesirable characteristic" (p. 31). Given that the chosen reference standard enters negatively into the utility function it seems perfectly plausible that people try to avoid unfavorable comparisons by comparing themselves downward, i.e., to select inferior comparison others. But why then does not everybody choose the lowest possible reference standard? Why do so many people "reach out to the stars" and set themselves goals and aspiration levels that are far beyond their capabilities? For one thing, the environment may place some constraints on the selection of comparison targets (see below). This, however, is not the only reason. There exists an additional rationale for comparisons which works into the opposite direction and which we will discuss in the following: self-improvement.

The idea behind the concept of self-improvement is that people perform better and are more successful if they set themselves high goals or reference standards. The reference group serving the goal of self-improvement therefore consists of people who perform better than the individual who is selecting the aspiration level. This kind of comparison is called 'upward comparison'. It has been demonstrated that upward comparison is often found among individuals who are "highly motivated to achieve a goal" (Wood and Taylor, 1991 p. 27). The idea that upward comparison may lead to self-improvement is familiar to everybody. ${ }^{1}$ Quite often we set ourselves

\footnotetext{
${ }^{1}$ Here are two examples: "We aim above the mark to hit the mark." (Ralph Waldo Emerson, writer). "Unless you have some goals, I don't think there's any way to get above the pack. My vision was always well beyond what I had any reason to expect." (John "Frenchy" Fuqua, running
} 
goals and compare our performance to others who are (currently) superior in order to motivate and encourage ourselves. The member of an athletic club who runs the 100 meters in 11 seconds may motivate himself by comparing himself to the best runner of the club who runs the 100 meters in 10.7 seconds. Laboratory research has shown that people who are performing a particular task do a better job in the presence of someone who does better (Seta, 1982) or if exposed to someone who is successful (Bandura, 1986). Setting high aspiration levels and comparing oneself to superior others motivates and helps improving. Summarizing their review of empirical research Major, Testa and Bylsma (1991) point to "the beneficial consequences of exposure to upward comparisons, especially with similar others, in situations where improved performance is perceived as possible. Under these conditions upward comparisons raise perception of self-efficiacy and motivate task persistence" (p. 252).

In a survey study we have investigated the idea that upward comparison motivates people to do better. This study was conducted with 255 students from the University of Zurich and the Polytechnical University of Zurich. Among other questions, students were asked whether they try harder if they have set themselves high goals. Possible answers range from 1 to 5 with 1 (= do not agree at all) to 5 (= totally agree). ${ }^{2}$ As can be seen from Table 1 about 80 percent of all subjects think that having high goals improves their own effort. Only 10 percent do not agree.

\section{Table 1}

How do downward comparison and upward comparison go together? Aren't they mutually exclusive? In our model we assume that both goals, self-enhancement and self-improvement are operative. People are facing a trade-off. If they set their goals too modestly they are content but they may not reach much. If, on the other hand, they constantly choose too ambitious goals they might perform quite well but at the same time they will suffer from disadvantageous and frustrating comparisons. Formally we show that this trade-off is optimally resolved such that the level of the comparison target increases in subjects' abilities. ${ }^{3}$

So far we have argued in favor of an actively selected comparison standard. However, in our model we do not assume that all comparisons are endogenous. Environmental factors clearly constrain and shape our reference standards. Depending on the specific context it may be likely that environmental factors are of great importance (e.g., in the classroom, Marsh, 1987). In other situations, exogenous factors are less influential. Decisive for the relative importance of exogenous vs. endogenous factors are the specific dimension of comparison, the availability of information and the pervasiveness and transparency of environmental factors (Diener and Fujita, 1997).

back).

${ }^{2}$ More details about the questionnaire are presented in Section 3.1.

${ }^{3}$ In colloquial terms this optimal balance of goal setting has often been recognized. Here is just one example: "Setting goals for your game is an art. The trick is in setting them at the right level neither too low nor too high." (Greg Norman, golf-pro). 


\subsection{The Formal Model}

According to the above discussion a utility function should capture the following features:

- Utility depends on the absolute outcome and on the relative outcome (i.e., on the outcome relative to some reference standard).

- The reference standard is partly exogenous and partly endogenous.

- The endogenous component of the reference standard is chosen to accomplish the goals of self-enhancement and self-improvement.

On a general level utility can thus be written as: $U_{i}=U\left(f\left(c_{i}, r_{i}\left(\bar{c}, \widetilde{c}_{i}\right)\right), k\left(e_{i}, \widetilde{c}_{i}\right)\right)$, where the utility of an individual $i$ depends on the utility of produced outcome $f$, and the costs of producing the outcome, given by $k$. Utility of the produced outcome is higher, the higher the absolute outcome $c_{i}$ and the lower the reference standard $r_{i}$, just as assumed in the standard comparison models. Different to the latter ones, however, $r_{i}$ is composed of an exogenous component $\bar{c}$ and an actively chosen component $\widetilde{c_{i}}$. Turning to the cost of producing outcome $k$, costs are increasing in the provided effort $e_{i}$, but are decreasing in the level of $\widetilde{c}_{i}$. This takes account of the positive motivational effects of higher goals. Taken together this specification of utility is a standard comparison model plus the actively chosen goal, $\widetilde{c_{i}}$, which is chosen to serve the goal of self-enhancement (low $\widetilde{c_{i}}$ in the $f$-term) and self-improvement (high $\widetilde{c_{i}}$ in the $k$-term).

In the following we step-by-step develop a specific utility function which satisfies the discussed requirements. Thereby we use particularly simple specifications that allow us to present our arguments in a straightforward manner.

Utility of produced outcome $(f)$. The utility of the produced outcome depends on the absolute outcome $c_{i}$, and on how this outcome compares to the reference standard denoted by $r_{i}$. In particular we assume that $f\left(c_{i}, r_{i}\right)=(1-\theta) c_{i}+\theta\left(c_{i}-\right.$ $\left.r_{i}\right)=\left(c_{i}-\theta r_{i}\right)$. This means that both the absolute outcome $c_{i}$ and the outcome relative to the reference standard $\left(c_{i}-r_{i}\right)$ contribute to an individual's utility. The importance of absolute vs. relative outcomes is determined by the values of $\theta$ and $(1-\theta)$, respectively, where $0 \leq \theta \leq 1$. The higher $\theta$, the more important are social comparisons where $\theta$ is an exogenously given parameter. The value of $\theta$ is determined by the comparison environment. The reference standard $r_{i}$ is itself a composition of two elements: the exogenously given standard $\bar{c}$ (which refers to forced comparisons) and the actively chosen component denoted by $\tilde{c}_{i}$. We assume that the total reference standard can be written as a linear combination of these two components, i.e., $r_{i}=q \bar{c}+(1-q) \tilde{c}_{i}$. The exogenously given parameter $q$ measures the strength of the forced comparison vis-à-vis to the actively chosen comparison. If $q=1$ the reference standard is completely exogenous to the individual. Summing up we will use the following expressions for $f: f\left(c_{i}, r_{i}\left(\bar{c}, \tilde{c}_{i}\right)\right)=c_{i}-\theta q \bar{c}-\theta(1-q) \tilde{c}_{i}$. 
The cost of producing outcome $(k)$. Every individual has a certain level of ability $a_{i}$ and an endowment of time (or maximum effort), which is normalized to one and assumed to be equal for all individuals. Supplying $e_{i}$ units of effort yields an outcome of $c_{i}=a_{i} e_{i}$. The cost of supplying this effort, however, depends not only on the exerted amount of effort but also on the choice of $\tilde{c}_{i}$. The same amount of effort will be perceived as more cumbersome if it is supplied to achieve a rather modest goal. This assumption captures the motivational arguments that we have discussed above. In setting high aspiration levels, people can motivate themselves and they will perform better. In particular we assume that the effort-costs can be written as: $k\left(e_{i}, \tilde{c}_{i}\right)=\frac{B}{\left(\tilde{c}_{i}\right)^{\delta \theta(1-q)}\left(1-e_{i}\right)}$, where $0 \leq e_{i} \leq 1$ is the chosen effort (or labor) supply and $B$ is a constant. The parameter $\delta$ measures the importance of self-improvement. Notice that the positive motivational effect of setting a high $\tilde{c}_{i}$ disappears when $\theta=0$ or when $q=1$. Since $\theta$ measures the importance of comparison per se it is clear that if $\theta=0$ holds, neither downward nor upward comparison serves any purpose. Put differently, if comparison is irrelevant, setting goals for self-improvement is irrelevant as well. Moreover, if $q=1$ there is no scope for the individual to actively determine the reference standard. In this case all comparison is forced by the environment.

Finally we assume that $U(f, k)=f^{\alpha} k^{-\beta}$, where $\alpha, \beta \geq 0$. We can combine our assumptions to arrive at the following representation of utility for individual $i{ }^{4}$

$$
u_{i}=\alpha \ln \left(c_{i}-\theta q \bar{c}-\theta(1-q) \tilde{c}_{i}\right)+\beta \ln \left(1-e_{i}\right)+\theta(1-q) \beta \delta \ln \left(\tilde{c}_{i}\right)
$$

Individual $i$ has three decision variables, $c_{i}, \tilde{c}_{i}$ and $e_{i}$ and maximizes (1) subject to the production function $c_{i}=a_{i} e_{i}$. The (earnings) ability $a_{i}$ is drawn from some distribution and individuals will thus generally differ with respect to their ability level. In our model there exists a continuum of individuals indexed by $i \in[0,1]$ who simultaneously maximize (1) subject to their production function. In maximizing utility each individual takes $\bar{c}$ as given. In equilibrium it must hold that the aggregated optimal performance decisions $c_{i}^{*}$ add up to the very level of $\bar{c}$ on which the optimal decisions are based, i.e., the following condition must hold: $\int_{i=0}^{1} c_{i}^{*}\left(\bar{c}^{*}\right) \mathrm{d} i=\bar{c}^{*}$. Given that $\bar{c}^{*}$ is endogenously determined by the interaction of the individuals, our model is a general equilibrium model. According to this specification higher performance of others increases an individual's reference standard. Since individual utility decreases in $\bar{c}$ there is a negative performance (or consumption) externality which is typical for social comparison models. ${ }^{5}$

\footnotetext{
${ }^{4}$ Note that thereby we use the monotonic transformation: $u_{i}=\ln U_{i}$ and leave out the constant $-\beta \ln B$. Furthermore we assume throughout the paper that the ability distribution is sufficiently compressed, i.e., $a_{i} \geq \tilde{a}, \forall i$ (where $\tilde{a}$ is defined in Appendix A). This assumption guarantees that in equilibrium $c_{i}-\theta q \bar{c}-\theta(1-q) \tilde{c}_{i} \geq 0$ and $\tilde{c}_{i} \geq 0$.

${ }^{5}$ Alternatively we could set up our model in a way that treats $\bar{c}$ as an exogenous component of the reference standard which is independent of the performance level of the other individuals. In this specification $\bar{c}$ could be interpreted as, e.g., a (physiologically given) subsistence level, a given requirement level (at school or at the job) or some standards imposed by parents, friends or
} 
In contrast to the existing models that include a concern for relative standing we allow that individuals actively alter their reference standards in order to serve the goals of self-enhancement $\left(\tilde{c}_{i}\right.$ in the first term of (1)) and self-improvement $\left(\tilde{c}_{i}\right.$ in the last term of (1)). However, altering one's reference standard is possible only if $q$ is smaller than 1 . If $q=1$ all comparison is forced and the reference standard is solely determined by the environment, given by $\bar{c}$. Thus, if $q=1$ holds, our model is equivalent to the existing 'forced comparison' models.

Notice further that our model also includes the standard neoclassical model where utility depends only on the absolute outcome $c_{i}$. This holds if $\theta=0$ which simply means that comparisons play no role. If $\theta=0$ holds, an individual therefore simply maximizes his outcome subject to $c_{i}=a_{i} e_{i}$. Thus, our model includes as two nested cases the 'forced comparison' model and the standard neoclassical model. For all cases where relative comparison matters $(\theta>0)$ and where individuals play an active role in determining their comparison targets $(q<1)$ we can study the endogenous determination of the reference standards. This will be done in the next section.

\subsection{Endogenous Reference Standards}

Our primary interest is to study how individuals optimally set their reference standards. Our main result is stated in Proposition $1 .^{6}$

Proposition 1 For $q<1$ the actively chosen component of a person's reference standard $\tilde{c}_{i}^{*}$ and a person's outcome $c_{i}^{*}$ is increasing in the person's ability, i.e., $\frac{\partial \tilde{c}_{i}^{*}}{\partial a_{i}}>0$ and $\frac{\partial c_{i}^{*}}{\partial a_{i}}>0$. As a consequence of $\frac{\partial \tilde{c}_{i}^{*}}{\partial a_{i}}>0$ the reference standard $r_{i}^{*}$ is increasing in the ability level as well. If $q=1$ the reference standard is exogenously given and independent of the ability level.

According to Proposition 1 people with high abilities have high reference standards or reference groups whereas people with lower abilities select low standards of comparison (see Figure 1). The intuition is simple: People with high abilities set high aspiration levels (i.e., they compare with 'richer', 'faster' and generally more successful people) in order to motivate themselves. Even though this has a negative effect in terms of self-enhancement, they can 'afford' to set high aspiration levels because given their high abilities - they will end up reaching high outcomes. People with low abilities on the other hand do not select high reference standards since they would never come close and would experience a high disutility from inferior achievements. Thus, the optimal reference standard for a given ability just balances the trade-off between the two goals of self-enhancement and self-improvement. Notice that the individual differences in reference standards are larger if subjects have more discretion,

neighbors. Note, however, that for the conclusions which we will derive in the following it does not matter (qualitatively) which specification of $\bar{c}$ is chosen.

${ }^{6}$ All proofs are collected in Appendix A. 
i.e., if $q$ is smaller. As shown in Figure 1 the slope of the 'reference standard line' is flatter the higher the value of $q$. For $q=1$ there is no choice to make anymore and all people have the same reference standard $\bar{c}$ independent of their abilities (see Figure $1)$.

Figure 1

\subsection{The role of forced comparison and the importance of relative comparison $(\theta, q)$}

In the last section we have shown that the reference standard increases in the ability of an individual. In this section we study the effects of $\theta$ and $q$ on the optimal choice of the outcome and the reference standard in more detail. The effects are summarized in the following two propositions:

Proposition 2 The more important relative comparison, i.e., the higher $\theta$, the higher is the outcome, i.e., $\frac{\partial c_{i}^{*}}{\partial \theta}>0, \forall a_{i}$. The actively chosen component of a person's reference standard $\tilde{c}_{i}^{*}$ and the reference standard $r_{i}^{*}$ decrease in $\theta$, i.e., $\frac{\partial \tilde{c}_{i}^{*}}{\partial \theta}<0$ and $\frac{\partial r_{i}^{*}}{\partial \theta}<0, \forall a_{i}$.

Proposition 3 The actively chosen component of a person's reference standard $\tilde{c}_{i}^{*}$ and the reference standard $r_{i}^{*}$ are increasing in $q$ if $a_{i}>\breve{a}$ and are decreasing in $q$ if $a_{i}<\breve{a}$ where $\breve{a}$ is a cut-off ability level (defined in Appendix A).

The intuition of Proposition 2 is as follows. If relative comparison becomes more important, people put more weight on their relative outcome, i.e., the outcome relative to the given reference standard. This makes it more valuable to perform better, relative to $r_{i}$. As a consequence, people work harder (increase their efforts $e_{i}$ ) and end up with higher levels of outcome (e.g., consumption). ${ }^{7}$ At the same time, people decrease the level of their reference standard as relative comparison becomes more important. This means that they insulate themselves from relative comparisons by selecting a lower reference standard or reference group. As Proposition 2 shows, however, the decrease in $\tilde{c}_{i}^{*}$ is not large enough to allow for an unchanged level in $c_{i}^{*}$ (and in efforts $e_{i}^{*}$ ). Although both $\tilde{c}_{i}^{*}$ and $r_{i}^{*}$, decrease, the total impact on the relative outcome component $\left(\theta r_{i}^{*}\right)$ is still strong enough such as to cause increases in optimal outcome and effort. Thus our model predicts that in societies where people put much emphasis on relative comparisons, people work harder and reach a higher standard of living.

According to Proposition 3 the choice of the reference group is also influenced by $q$. The sign of the effect of $q$ on the reference standard depends on the ability level, however. For low-abilities individuals $\left(a_{i}<\breve{a}\right)$ the effect is negative. This means

${ }^{7}$ This result also holds in standard forced-comparison models (Hof, 1999). 
that people with lower abilities reduce their reference level as the forced comparison component becomes more important, while the opposite holds for people with high abilities $\left(a_{i}<\breve{a}\right)$. This result is also shown in Figure 1. The intuition behind this behavioral pattern is most easily seen if one assumes for a moment that the average consumption level $\bar{c}^{*}$ does not change in $q$, i.e., $\frac{\partial \bar{c}^{*}}{\partial q}=0 .{ }^{8}$ In this case the effect of a change of $q$ on the actively chosen component of the reference standard is: $\frac{\partial \tilde{c}_{i}^{*}}{\partial q}=\frac{\delta \beta \theta}{\alpha+\beta(1+\delta \theta(1-q))}\left(\tilde{c}_{i}^{*}-\bar{c}\right)($ see Appendix A). The effect can be positive or negative, depending on the sign of $\tilde{c}_{i}^{*}-\bar{c}$. An individual with $\tilde{c}_{i}^{*}>\bar{c}$ (which is equivalent to $a_{i}>\hat{a}$, see Appendix A) will increase his actively chosen component $\tilde{c}_{i}$ while the opposite is true for an individual with $\tilde{c}_{i}^{*}<\bar{c}$ (or $a_{i}<\hat{a}$ ). The intuition for the positive or negative adjustment stems from the fact that individuals want to offset the change in the reference standard $r_{i}$ after a change in $q$. Remember that $r_{i}$ is a linear combination of the exogenous (forced) component $\bar{c}$ and the actively chosen component $\tilde{c}_{i}$. If the relative weight of the exogenous component increases (as $q$ increases) the level of $r_{i}$ is not optimal anymore. In order to adjust $r_{i}$ back to the optimal level, individuals therefore have to change $\tilde{c}_{i}$ to counterbalance the increased weight of $\bar{c}$. Individuals for whom $\tilde{c}_{i}>\bar{c}$ have to increase $\tilde{c}_{i}$ while those for whom $\tilde{c}_{i}<\bar{c}$ have to decrease $\tilde{c}_{i}$ in order to keep the optimal reference standard unchanged.

If one relaxes the assumption that $\frac{\partial \bar{c}^{*}}{\partial q}=0$, the effect of a change in $q$ on $\tilde{c}_{i}$ also depends on the effect of $q$ on the equilibrium value of $\bar{c}^{*}$. In particular it is given by: $\frac{\partial \tilde{c}_{i}^{*}}{\partial q}=\frac{\delta \beta \theta}{\alpha+\beta(1+\delta \theta(1-q))}\left(\tilde{c}_{i}^{*}-\bar{c}^{*}-q \frac{\partial \bar{c}^{*}}{\partial q}\right)$. The intuition is similar to the one given above and is discussed at more length in Appendix A. The only difference is that the sign of $\frac{\partial \tilde{c}_{i}^{*}}{\partial q}$ now also depends on the sign of $\frac{\partial \bar{c}^{*}}{\partial q}$ and that the cut-off ability level $\breve{a}$ (for which $\frac{\partial \tilde{c}^{*}(\breve{a})}{\partial q}=0$ ) is thus a somewhat more complicated expression (given in Appendix A). If $\frac{\partial \bar{c}^{*}}{\partial q}<0$, e.g., the impact of an increase in $q$ on the reference standards will be positive $\left(\frac{\partial \tilde{c}_{i}^{*}}{\partial q}>0\right)$ for a larger number of individuals than before, i.e., $\breve{a}$ is relatively small.

The reaction of $\bar{c}^{*}$ on $q$ thereby depends on the structural parameter values of the model. For small values of $\alpha$ and $\theta$ and high values for $\beta$ and $\delta$, e.g., $\frac{\partial \bar{C}^{*}}{\partial q}<0$. In this situation a relatively small percentage of individuals will react to an increase in $q$ by lowering $\tilde{c}$. A large percentage on the other hand will increase their goals. This is a reasonable result since in this case utility contributions of absolute and relative outcome (given by $\alpha$ and $\theta$ ) are rather unimportant while the utility impact of the motivational forces (given by $\beta$ and $\delta$ ) are strong.

\section{Empirical Evidence and Applications}

In this section we present empirical evidence that supports the main results of our model. In Section (3.1) we directly test the main content of Proposition 1, namely

\footnotetext{
${ }^{8}$ This corresponds to the interpretation of the model given in footnote 5 .
} 
whether it is, in fact, the case that the reference standard increases in abilities. In Section (3.2) we discuss empirical evidence from the "social perception" literature. In particular, we show that our model organizes important data of minimum income studies (3.2.1), happiness studies (3.2.1) and subjective social class studies (3.2.3).

\subsection{Reference standards and abilities}

Empirical support for Proposition 1 comes from a variety of studies. We want to start this section with the results of a survey that we have conducted with 255 students from the University of Zurich and the Polytechnical University of Zurich. The purpose of the questionnaire study was to explore whether students with higher abilities set themselves higher goals as suggested in Proposition 1. The students were invited to a computer lab were they were given short instructions and the questionnaire. They received a small show-up fee for coming.

The two most important questions are about (i) students' aspired degree on the final university examination and (ii) students' high-school graduation degree. The first variable is our measure of students' aspirations, i.e., the actively chosen component $\widetilde{c}_{i}$. It is the average grade of students' "final university examination", which is taken at the end of the first-degree university study. ${ }^{9}$ This variable is very well suited for our research purpose for two reasons. First, it measures aspirations in a highly relevant dimension, because getting a good degree is the ultimate goal in a student's career. Second, grades can be measured and compared quite easily. Notice that we did not ask students about their expected degrees. Rather we explicitly asked them to indicate their aspired examination degree. The second variable "high-school graduation degree" is our proxy for a student's intellectual abilities. The rationale to use this variable as an indicator for ability is our expectation that on average better degrees are clearly correlated with the ability to get a good diploma degree. ${ }^{10}$ Both the grade on the final university examination and the high-school graduation degree, are numbers between 1 and 6 , where 4 is just enough to pass the examination and 6 is excellent.

Given that the latter degree is an independent measure of a student's abilities we should - according to Proposition 1 - find a positive correlation between aspired final university examination degree and the high-school graduation degree. This is in fact the case. The nonparametric Spearman rank correlation coefficient is positive and significant at any conventional level $(\mathrm{p}<.0001)$. However, it could be argued that other variables additional to abilities shape students' aspirations. In order to control for these additional factors of influence we asked two sets of control questions (see Table 2). The first set contains socioeconomic questions like sex, age, field of study, community size, disposable income and working hours. The second block of control questions contains eight questions taken from the General Social Survey (GSS)

\footnotetext{
${ }^{9}$ This degree is called "Lizentiat", which Swiss students typically take at an age of about 25.

${ }^{10}$ In Switzerland this examination is called "Matura", which is typically taken at the age of 19.
} 
questionnaires. ${ }^{11}$ Here students had to indicate the importance of different reasons to 'get ahead'.

\section{Table 2}

Table 2 presents three ordered probit estimations of students' aspirations. The first model contains only abilities (high-school graduation degree) as an explanatory variable. As can be seen in Table 2, abilities have a positive and highly significant effect. In the second model we include a set of socio-economic control questions. Notice that sign and significance of abilities remains unchanged. Two other variables enter significantly, namely sex and technical department. The negative sign associated with the variable sex indicates that female students have lower aspirations compared to males. This holds even though female students have slightly higher abilities (better high school grades) than their male colleagues.. The observation that women are less optimistic (or more modest) confirms to what has been found in related studies (Zuckerman, 1979, Maccoby and Jacklin 1974). Moreover, it is compatible with the negative effect of the 'male dummy' in regressions on happiness (Clark and Oswald 1996): If males have higher aspirations than women, they should ceteris paribus have lower happiness scores as well.

The variable technical department measures whether the corresponding student studies a 'technical' subject such as physics, chemistry or mathematics. The other subjects comprise medicine, law, social sciences or humanities. We control for this difference because in Zurich degrees are typically lower in the technical departments. Therefore it is not surprising that the corresponding students have significantly lower aspirations - even though they have significantly higher high-school graduation degrees (Mann-Whitney $(\mathrm{p}<.067$, two sided $)$ ).

The third model includes answers to the question: "Please indicate for all following reasons, how important they are for getting ahead". The answers allow us to further control for possible omitted influences. As shown in Table 2 (Model 3) the coefficient on ability remains basically unchanged and stays highly significant. The same holds for the variables sex and technical department. The only new variable which enters the regression at a conventional level of significance is ambition. The positive sign means that people who think that ambitions are important report higher aspiration levels. This is consistent with the view that people who put strong emphasis on selfimprovement, also put more weight on upward comparison. Two further variables are weakly significant: The variable well educated parents enters negatively which means that students stating that well educated parents are important for getting ahead have lower aspirations. This result is compatible with the view that people who think that their success is largely determined by forces that are out of their own control don't have a reason to put much weight on self-improvement goals. Rather they lower their aspirations to serve self-enhancement goals. The variable hard work also enters

\footnotetext{
${ }^{11}$ Cf. 1987 ISSP Module: Social Inequality (Qs. 186, 717-730).
} 
weakly negatively. We speculate that individuals with low abilities regard hard work as a substitute for their lacking talents. Notice that this interpretation is consistent with our model where equilibrium effort (work) is decreasing in ability (equation (8), where $\left.\frac{\partial e_{i}^{*}}{\partial a_{i}}<0\right)$.

Summarizing our results we find strong evidence for the hypothesis that the reference standard increases in the ability level. This holds after controlling for socioeconomic and personal characteristics.

\subsection{Social Perception Studies}

There exists a considerable literature that deals with people's perception of various economic and social situations: how happy and satisfied they are with their jobs, health or life in general (Diener et al. 1999), how they assess their place in society or their social class, what resources they consider necessary in order to achieve a certain standard of living etc. For a long time these empirical analyses were not at the core of economic research (although they were prominent in the psychological and sociological literature), but this has changed over the recent years (compare, e.g., "Controversy: Economics and Happiness", Economic Journal 107(445), 1997; di Tella et al., 1998; Frey and Stutzer, 1999). From an economist's point of view these studies are interesting for (at least) two reasons: First, they offer first-hand information about the form of individual utility functions and about the factors that exert influence on them. Secondly this literature is important since the subjective perception of situations might have considerable influence on economic and political behavior, e.g., on the occurrence of crime, social unrest and revolutions, on voting behavior, on the effort decisions of workers, and on migration.

In the following we want to present empirical observations from different, but related fields of the social perception literature. We show that these observations are supportive for our model, but hard to explain by the standard neoclassical or by the forced comparison model.

\subsubsection{Minimum Income}

Minimum income studies are part of the "subjective approach to the measurement of income inequality" (Amiel, 1998). These studies are built on the "Minimum Income Question" (MIQ), that is formulated, e.g., like: "What income do you consider to be minimally necessary for your household to make ends meet?" (de Vos and Garner, 1991, p. 269). ${ }^{12}$ Answers to the MIQ are often used to derive subjective poverty lines that can be viewed as alternatives to other existing (absolute and relative) poverty definitions (Hagenaars and van Praag, 1985).

\footnotetext{
${ }^{12}$ A slightly different formulation can be found in Colasanto et al., 1984, p. 129. The MIQ and the entire approach was introduced in Goedhart et al., 1977.
} 
The main empirical finding is that the minimum income individuals consider necessary to make ends meet $\left(c_{i}^{\min }\right)$ rises in their own income $\left(c_{i}\right)$, i.e., $\frac{\partial c_{i}^{\mathrm{min}}}{\partial c_{i}}>0 .{ }^{13}$ Moreover the elasticity of responses lies typically around $0.5^{14}$, i.e., the minimum income rises less than one to one with own income.

A straightforward operationalization of the concept of poverty (or of the minimum income $c_{i}^{\min }$ ) in our model is to define it as the level of income that is necessary for an individual to prevent his fall into complete misery, given as a utility of $u_{i}=$ $-\infty$. In particular we would expect that individuals living in our model world would answer the minimum income question by equating $c_{i}^{\min }=\theta r_{i}^{*}$ since in this case utility approaches $-\infty$ (compare (1)). Naturally, in answering this question individuals treat $\tilde{c}_{i}^{*}$ and $\bar{c}^{*}$ as given, while their total income is observed by the researcher. The value of $c_{i}^{\min }$ can easily be calculated (see Appendix A). Assuming $\theta>0$ and $q<1$ it is given as follows:

$$
c_{i}^{\min }=\frac{\theta q \alpha}{\alpha+\gamma \theta(1-q)} \bar{c}^{*}+\frac{\gamma \theta(1-q)}{\alpha+\gamma \theta(1-q)} c_{i}^{*}
$$

From equation (2) it immediately follows that subjective minimum income $c_{i}^{\min }$ is increasing in own income. In particular we get that: $\frac{\partial c_{i}^{\min }}{\partial c_{i}^{*}}=\frac{\gamma \theta(1-q)}{\alpha+\gamma \theta(1-q)}<1$. This result conforms well to the results of the empirical investigations of the MIQ.

For the forced comparison model $(q=1)$ on the other hand the answer would be given by $c_{i}^{\min }=\theta \bar{c}^{*}$ (equation $(2)$ for $q=1$ ) and therefore $\frac{\partial c_{i}^{\text {min }}}{\partial c_{i}^{*}}=0$. The forced comparison model thus predicts that all individuals give the same answer to the MIQ, which is clearly at odds with the empirical data.

Similarly the standard neoclassical model with $\theta=0$ faces problems to explain these findings. First of all in this model it is not at all clear what is meant by minimum income since the concept of basic needs is completely void in this formulation. The closest one can get within the neoclassical framework is by defining some absolute level of poverty (or some absolute level of "subsistence consumption"), but then the answer to the MIQ should (i) not increase with income in a cross-section and should (ii) not increase over time. Both predictions are strongly contradicted by the data. ${ }^{15}$

Summing up, our model is compatible with the results from the MIQ studies, while neither the standard neoclassical model (augmented by a subsistence level) nor the standard relative consumption model (with $q=1$ ) can explain these regularities.

\footnotetext{
${ }^{13}$ This holds even after controlling for other variables like family size, age structure of the households, education etc.

${ }^{14}$ Studies include: Goedhart et al. (1977), Danzinger et al. (1984), Kilpatrick (1973), van Praag et al. (1980), Stanovnik (1992). Colasanto et al. (1984, p. 136), e.g., report that if 12 separate previous estimations are combined the median value is approximately 0.49 .

${ }^{15}$ On point (ii) see Roberti, 1980.
} 


\subsubsection{Happiness}

A large field of the social perception literature deals with the question of satisfaction and happiness (Diener et al. 1999; Easterlin, 1995; Oswald, 1997). Thereby people are asked how happy they feel (on some scale between, say, 1 and 10). These answers can then be used to investigate the social and economic determinants of happiness (e.g., income, martial status, employment status etc.). ${ }^{16}$ The empirical evidence found in this literature conforms to the predictions of our model. In particular the data suggest that people (i) care about their relative standing, (ii) that they have different reference groups and (iii) that they can shield themselves from all too unfavorable comparisons. The first conclusion can be derived from the fact that average national happiness levels do not increase despite strongly increasing levels of average income (Easterlin, 1973, 1995). This finding is usually interpreted in a way that people have a strong concern for relative income, just as assumed in our model. Results (ii) and (iii) are derived from the observation that in most happiness studies a majority of respondents indicates to be "happy" or "very happy". In Clark and Oswald (1996), e.g., more than 75 percent of the asked subjects indicated a satisfaction level of 5, 6 and 7 on a range between 1 to 7 . A similar observation is made by Easterlin (1973) who finds that even in the lowest income group 84 percent indicate that they are "happy" or "very happy". If all comparison was forced and people compared themselves with the mean income (of their region or country) one would probably expect that about half of the people are above and the other half are below that average (Diener and Fujita, 1997, p. 344). In our model, however, people are able to preserve and gain high levels of happiness by using coping strategies. ${ }^{17}$

Happiness studies also provide evidence for the positive correlation between abilities and aspirations. Clark and Oswald (1996), e.g., report that "counter to what neoclassical economic theory might lead one to expect, highly educated people are less content" (p. 373). Controlling for income, the effect of education on reported well-being is shown to be negative. Similar results are presented in Warr (1992) or Klein and Maher (1966). In Blanchflower and Oswald (1992) work satisfaction was lowest for those workers who have a college degree. If subjective well-being was solely defined on the absolute income (as assumed in standard neoclassical models) education should not (negatively) enter the utility of people. On the other hand, in a social comparison model with an exogenously given comparison level this stylized

\footnotetext{
${ }^{16}$ From a theoretical point of view these studies are somewhat controversial as they involve concepts like interpersonal comparability of utility and assumptions about functional forms and mappings of continuous functions on discrete and finite scales (e.g., van Praag, 1993).

${ }^{17}$ The use of coping strategies is also typical for people facing major medical problems (Affleck and Tennen 1991). It is often reported that people with medical problems compare themselves downward. In our model an accident or illness may be interpreted as a negative ability shock, leading to lower abilities and lower reference standards. This 'coping strategy' helps to avoid unfavorable comparisons. It is documented that subjective well-being decreases after the accident, but only a little bit (Diener et al. 1999).
} 
fact cannot be explained either. If, e.g., the commonly hold reference standard in a given environment is given by average income, changing educational levels and leaving income constant should not have any impact on utility and subjective well-being. A natural way to interpret these data is to assume that the reference standard is not exogenously given and that it does vary with individual characteristics such as education or ability. In fact this is how Clark and Oswald (1996) interpret their data. They note that the negative impact of education on reported satisfaction "may be consistent with the view that utility depends on the gap between outcomes and aspirations, and that education raises aspiration targets" (p. 360-361). If we interpret $a_{i}$ as a person's education, Proposition 1 states that for two people with equal income but different levels of $a_{i}$, the person with the higher ability will have lower subjective well-being. Higher abilities lead to higher aspiration levels and for a given success (e.g., income) the person with a lower aspiration level feels better about what he has achieved. ${ }^{18}$

\subsubsection{Subjective Social Class}

There exists an additional piece of evidence in the literature on social perception that supports the predictions of our model. This evidence involves questions about people's subjective social class. Surprisingly, this data has not yet been discussed in the literature. The subjective social class data we want to refer to, come from the ISSP (International Social Survey Programme) that was carried out in 1992 on the topic of social inequality in 18 countries. In this survey a question (V73) was included that reads like: "In our society there are groups which tend to be towards the top and groups which tend to be towards the bottom. Below is a scale that runs from top to bottom. Where would you put yourself in this scale?"19 We interpret the answer to this subjective-social-class question as a proxy for people's perception of their position in the income distribution. In doing so we rely on the fact that in most existing studies on this topic income is one of the most important determinants of social class. ${ }^{20}$ It seems, therefore, quite reasonable to assume that people, when stating their self-rated social class, indicate at the same time their perceived position in the income distribution. Thus, we can compare a person's indicated (subjective) rank to his objective rank in the income distribution. The latter is constructed from

\footnotetext{
${ }^{18}$ To be precise in our model there is a 1:1 correspondence between ability and income. But this could be easily changed by introducing uncertainty or non-earned income into our model. The first could be done, e.g., by writing $c_{i}=a_{i} e_{i} \varepsilon_{i}$, where $\varepsilon_{i}$ is a random variable with $E[\varepsilon]=1$. The latter by defining $c_{i}=a_{i} e_{i}+W_{i}$, where $W_{i}$ represents individual $i$ 's wealth. Both reformulations give rise to the pattern mentioned in the text.

${ }^{19}$ The scale ran from 1 (top) to 10 (bottom), but we have reversed the order such as to contrast it with decile-data from the actual income distribution. For a detailed description on the data see Appendix B.

${ }^{20}$ On this point see Argyle 1994. A more detailed investigation of the perception of subjective social class (which we plan for the future) should include other factors of influence like education, profession, social background etc.
} 
the reported household's income (V116 in the ISSP-data).

For someone who is a perfectly informed, unbiased observer of his own situation the objective and subjective position in the income distribution should coincide. In Figure 2 we show how persons with a certain rank in the income distribution on average see their social class, first for a sample of five countries taken together and then for the various countries separately. The graph in the upper left corner, e.g., shows that in the total sample individuals in the first decile of the income distribution perceive their subjective class as approximately 4.5, while people in the highest decile perceive their class as around 6.5. A similar pattern emerges for the countries taken separately. ${ }^{21}$ If all individuals were unbiased observers of their own situation then the average answers of individuals located in the first decile should be 0.5 , while in the tenth decile it should be 9.5. The differences between the actual average answers and the answers of those unbiased individuals (for the sample of five countries taken together) are illustrated in Figure 3.

\section{Figure 2 Figure 3}

From Figures 2 and 3 we can draw two conclusions. First the perceived rank in the income distribution (or the subjective social class) increases with the objective rank in the income distribution. Richer individuals do in fact "know" or "perceive" that they are richer. Secondly, however, one can also observe that there is a clustering around the middle categories (5 and 6). Most people seem to think that they belong to the middle class and earn about average incomes (the actual line of answers is much flatter than it should be for unbiased observers).

We think that the social comparison model presented in this paper offers a straightforward explanation of these subjective social class data. ${ }^{22}$ As we have shown in Proposition 1 the reference standard $r_{i}$ increases in income (or ability). Individuals with above-average income will thus have friends, peers and reference groups that have above average incomes and consumption profiles themselves, i.e., they will have $r_{i}>\bar{c}$. As a consequence their social environment is not a representative subsample of their society at large but will be biased towards the upper ends of the distribution. By the same token the low income groups will have reference groups with below-average incomes $\left(r_{i}<\bar{c}\right)$ and their social environment will be biased towards the lower ends of the income distribution. When asked about their social standing or class it is natural to assume that people are influenced by their "biased" reference groups and social environments, even if they try to give "objective" answers. The individuals in the

\footnotetext{
${ }^{21}$ For some countries specific values are missing (decile 2 for the UK and decile 3 for Italy). This is because in these cases the income categories in the questionnaire were too broad in order to transform them into decile values.

${ }^{22}$ We do not think that these findings can be explained by a general tendency to answer such questions with middle categories. If this was the case it should also be true for the happiness studies, where, as we have seen, a majority of respondents puts itself into the highest categories ("very happy", "happy" etc.).
} 
upper deciles of the distribution will then overestimate the "true" level of average income and thus underestimate their own rank in the distribution. Individuals in the lower deciles on the other hand will underestimate the true level of average income and will accordingly overestimate their own position. This corresponds to a remark by Okun: "Most people [at the top 5 percent of the income pyramid] consider themselves middle-income rather than upper-income and are shocked to learn that their incomes exceed those of nineteen out of twenty American families. But it is only by comparison with their own friends, neighbors, and coworkers that they are just average." (Okun, 1975, p. 68). This "false sampling" is exactly what our model predicts, since the endogenously chosen reference standards increase in income and ability. The "flatness" of the subjective-social-class line (Fig. 3) can thus be explained by these twofold misperceptions: the overestimation of their position by the lower deciles and the underestimation by the upper deciles.

Summarizing the discussion so far, our model is compatible with two important pieces of empirical evidence from the literature on social perception: the high level of general happiness and the occurrence of systematic misperceptions of individuals' social position. Our model predicts this outcome, since individuals will use coping strategies in order to shield themselves from unfavorable comparisons. As the data show, these strategies are good for personal satisfaction but bad for objective selfassessment.

The feeling of happiness and the perception of one's social class are thus not independent areas, but they are interrelated. People with low reference standards will overestimate their class and report - ceteris paribus - high levels of satisfaction, whereas individuals with high reference standards should underestimate their class and declare themselves as less happy. In order to test these predictions of our model on an individual level one needs to have a data set that includes questions about both items. Unfortunately this is not the case for the data set used in this section (ISSP 1992). As a first attempt to test the theory, however, we can also use aggregate data. Our model predicts that the average level of happiness should be higher in countries where a larger proportion of people overestimate their social position and where, as a consequence, the average response to the subjective social class question is higher as well.

The upper part of Table 3 reports information on these questions for a sample of 18 countries. The happiness data (HAPPY) are taken from the World Database of Happiness as reported in Veenhoven (2000) and they are the average responses (on a 1-4 scale) to the question: "Taking all together how happy would you say you are?" 23 The figures reveal interesting differences in the happiness scores, ranging from 2.33 (Bulgaria) to 3.36 (Sweden). In general happiness is lowest in the former communist countries, whereas the rather poor Philippines have a similar happiness score (3.08) as, e.g., Canada (3.05) or former West-Germany (3.04).

\footnotetext{
${ }^{23}$ The data were thereby collected in the early 90's which is also the survey time of our second major data source, the ISSP 1992.
} 
The other data are taken from the ISSP 1992 survey. MEANSSC are the national average responses to the subjective social class question $(S S C)$. OVER gives the proportion of respondents in a country who overestimate their position in the income distribution (measured by the decile $D E C_{i}$ ), i.e., for whom $S S C_{i}>D E C_{i}$. UNDER, on the other hand, measures the share of people who underestimate their social position (i.e., $\left.S S C_{i}<D E C_{i}\right) .{ }^{24}$ For the latter variables we lose some observations, either because of missing income data or because the given income categories were too broad to allow for the construction of income deciles. The average perception of the subjective social class is again lowest in Bulgaria (3.84) and highest in New Zealand (5.99). The proportion of people who underestimate their true social position is highest in Poland (66.42 percent) and lowest in Austria (44.48 percent).

In the lower part of Table 3 we show the correlation between happiness and the variables that measure individuals' social perception. The results from the Spearman rank test show that happiness and average subjective class are positively correlated as our model predicts. The Spearman rank correlation coefficient $\rho=0.71$ is significant at the 1 percent level, confirming the hypothesis that people in those countries are happier who have a higher perception of their social standing. By the same token the average level of happiness is higher (lower) in those countries where individuals tend to overestimate (underestimate) their own social position (a $\rho$ of 0.66 and of -0.69 , respectively, both significant at the 5 percent level). We thus find support for the predictions of our model even (and perhaps surprisingly) in highly aggregated data.

The results of this section offer new insights into the determinants of happiness. In particular they add a new aspect to the discussion whether income has a positive effect on happiness (Easterlin, 1974, 1995; Diener et al., 1999). The preceding discussion suggests that it is perceived income (absolute or relative) and not actual income that has an influence on subjective well-being. The weak or non-existing correlation between current income and happiness, often observed in the data, could thus be explained by the fact that current income is a bad proxy for perceived income and that the latter is important for subjective well-being.

\section{Discussion}

As the previous sections have shown there exists ample evidence for the fact that people have different reference standards and reference groups. Our model explains this observation by assuming that - given their abilities - people choose their reference standards in an optimal way, high enough to elicit effort and low enough to prevent unnecessary feelings of failure and deprivation. We have provided empirical evidence that abilities do in fact shape aspirations and that empirical regularities reported in happiness studies, minimum income and subjective class studies conform to the

\footnotetext{
${ }^{24}$ The percentage share of people who have an accurate picture of their position (i.e., with $S S C_{i}=$ $\left.D E C_{i}\right)$ is thus given by $100-O V E R-U N D E R$.
} 
perspective advocated in this study.

There exists, however, an alternative explanation for heterogenous reference standards, the so-called habit-formation approach. According to the latter, reference standards are a consequence of people's past experience. This approach has often been used to explain the empirical regularities outlined above, e.g., the findings in the minimum income studies: "Of course, $y_{i}^{\min }$ is subjective - that is, it may depend on the individual's personal circumstances, it may be subject to reference group influences, or it may depend on previous consumption levels" (Colasanto et al., 1984, p. 127f; also van Praag, 1993, p. 379; Hagenaars and van Praag, 1985, p. 147).

What makes this approach similar to ours is the fact that reference groups are not assumed to be identical for all individuals. Given an individual history, habits may form individually as well. The main difference to the approach suggested in this paper, however, concerns the passive nature of the habit formation process. In a habit-formation model people have no discretion whatsoever to shape the comparison process. Instead it is assumed that reference standards are formed in a mechanical way. No motivational issues are involved and people are not forward looking. In our view, this perspective is rather unusual for economists who are used to stress the importance of rational choice.

This is not to say that habit formation is irrelevant. Quite to the opposite we believe that past performance is an important determinant for people's reference standards. In fact, we can easily incorporate the habit formation concept into our model by interpreting $\bar{c}$ as determined by past performance. However, even if past performance or habits enter $r_{i}$, individuals still have some discretion to shape $r_{i}$ in a self serving manner (as long as $q<1$ ). As a consequence, our model would allow two individuals with identical past performance to differ with respect to their reference standards, an implication which is impossible to derive with a pure habit formation model.

Another possible extension of our model concerns dynamic patterns. It seems to be a quite robust finding that happiness and job satisfaction increase in age or show some sort of U-shape pattern (Clark and Oswald, 1996, Clark, Oswald and Warr 1995). Similarly, various MIQ-studies have found that the stated minimum income decreases - ceteris paribus - with age. Stanovnik (1992) finds a negative coefficient for age in his 1988 survey of Slovenian households (p. 60), while de Vos and Garner (1991) estimate a quadratic relationship between stated minimum income and age, where "minimum perceived income peaks at age 51 for the U.S. and at age 58 for the Netherlands." (ibd., p. 275). Our model offers a possible explanation for the observed age pattern of happiness and minimum income studies: The point is that the discounted value of better performance levels decreases over time. As a person gets older, setting high aspirations in order to motivate and to reach high performance has "less time to materialize", i.e., to increase lifetime utility. Technically, $\delta^{\prime}(t)<0$. With the approaching end of life, the trade-off between effort cost reducing upward comparisons and self-enhancement is therefore resolved in favor of the latter. As a 
consequence of the decrease in aspirations, comparisons become more favorable, i.e., people are more satisfied with their job, are happier and indicate lower minimum incomes. This aspiration based interpretation of the observed age patterns is supported by several authors (e.g., Clark, Oswald, Warr 1995; Stanovnik, 1992). ${ }^{25}$

The main purpose of the present paper is to stress the active role people play in selecting comparison targets. Allowing people to choose their Joneses does not mean that comparison becomes completely arbitrary, however. As we have shown in our simple theoretical framework, the 'optimal Joneses' depend on the goals of comparison and individually different characteristics, such as abilities. We think that the approach suggested in this paper yields a realistic view on social comparison processes. At least more realistic than the undersocialized standard economic approach (with its neglect of social comparison) and the oversocialized approach of forced comparison.

\footnotetext{
25 "We expect a negative sign for this coefficient [i.e. age], since older households have not only lower aspirations but presumably also objectively lower requirements. [...] Variables denoting age of head of household and home ownership were introduced in our analysis, as proxies for income aspirations." (Stanovnik, 1992), p. 61, 68). "Age seems to be a proxy for realism. The options of the young become the constraints of the old, and they are perceived that way. Unattainable goals are abandoned as time passes." (Kantona et al., 1971, quoted in Stanovnik, 1992, p. 66).
} 


\section{Appendix A - Derivations and Proofs}

Each individual maximizes the utility funcion (1) subject to the budget constraint $c_{i}=e_{i} a_{i}$. The (earnings) ability $a_{i}$ is different between individuals and is the only kind of heterogeneity in our model. ${ }^{26}$ We assume that the individual treats $\bar{c}$ as being independent of his own consumption decision (i.e., in maximizing he sets $\frac{\partial \bar{c}}{\partial c_{i}}=0$ ). Substituting for $e_{i}$ in the budget constraint the maximization problem is as follows:

$$
\max _{\left\{c_{i}, \tilde{c}_{i}\right\}} u_{i}=\alpha \ln \left(c_{i}-\theta q \bar{c}-\theta(1-q) \tilde{c}_{i}\right)+\beta \ln \left(1-\frac{c_{i}}{a_{i}}\right)+\gamma \theta(1-q) \ln \left(\tilde{c}_{i}\right),
$$

where $\gamma \equiv \beta \delta$. The first order conditions are:

$$
\begin{gathered}
\frac{\partial u_{i}}{\partial c_{i}}=\frac{\alpha}{c_{i}-\theta q \bar{c}-\theta(1-q) \tilde{c}_{i}}-\frac{\beta}{a_{i}-c_{i}}=0 \\
\frac{\partial u_{i}}{\partial \tilde{c}_{i}}=-\frac{\alpha \theta(1-q)}{c_{i}-\theta q \bar{c}-\theta(1-q) \tilde{c}_{i}}+\frac{\gamma \theta(1-q)}{\tilde{c}_{i}}=0
\end{gathered}
$$

As can be seen from (4) in the case where $\theta=0$ or $q=1$ the second FOC is fulfilled for all values of $\tilde{c}_{i}$. In this cases the personal goals $\tilde{c}_{i}$ "disappear" from the utility function (1) and thus they become irrelevant for utility maximization. As long as $\theta>0$ and $q<1$ we can use the FOCs to calculate: $\tilde{c}_{i}=\delta\left(a_{i}-c_{i}\right)$. From (3) we can derive: $c_{i}(\alpha+\beta)=\alpha a_{i}+\beta \theta q \bar{c}+\beta \theta(1-q) \tilde{c}_{i}$. For later reference we will denote them as:

$$
\begin{gathered}
\tilde{c}_{i}=\delta\left(a_{i}-c_{i}\right) \\
c_{i}=\frac{\alpha}{\alpha+\beta} a_{i}+\frac{\beta \theta q}{\alpha+\beta} \bar{c}+\frac{\beta \theta(1-q)}{\alpha+\beta} \tilde{c}_{i}
\end{gathered}
$$

Combining these two equations we can find an expression for $c_{i}$ depending on $\bar{c}$, i.e., $c_{i}=\frac{\alpha+\gamma \theta(1-q)}{\alpha+\beta+\gamma \theta(1-q)} a_{i}+\frac{\beta \theta q}{\alpha+\beta+\gamma \theta(1-q)} \bar{c}$. In equilibrium it must hold that $\int_{i=0}^{1} c_{i}\left(\bar{c}^{*}\right) \mathrm{d} i=$ $\bar{c}^{*}$ and using this aggregation condition we can finally derive: $\bar{c}^{*}=\frac{\alpha+\gamma \theta(1-q)}{\alpha+\beta(1-\theta q)+\gamma \theta(1-q)} \bar{a}$, where $\bar{a}=\int_{i=0}^{1} a_{i} \mathrm{~d} i$ denotes the average level of abilities in the considered group. It is then straightforward to calculate the equilibrium values (denoted by "stars") of the main variables:

$$
\begin{aligned}
c_{i}^{*} & =\frac{\alpha+\mu}{\alpha+\beta+\mu} a_{i}+\frac{\beta \theta q}{\alpha+\beta+\mu} \bar{c}^{*} \\
e_{i}^{*} & =\frac{\alpha+\mu}{\alpha+\beta+\mu}+\frac{\beta \theta q}{\alpha+\beta+\mu} \frac{\bar{c}^{*}}{a_{i}}
\end{aligned}
$$

\footnotetext{
${ }^{26}$ This distinguishes our approach from Frank (1984) where the "sorting into different ponds" occurs, because individuals put different weights on absolute and relative standing.
} 


$$
\begin{gathered}
\tilde{c}_{i}^{*}=\frac{\gamma}{\alpha+\beta+\mu} a_{i}-\frac{\gamma \theta q}{\alpha+\beta+\mu} \bar{c}^{*} \\
\bar{c}^{*}=\frac{\alpha+\mu}{\alpha+\beta(1-\theta q)+\mu} \bar{a} \\
r_{i}^{*}=q \bar{c}^{*}+(1-q) \tilde{c}_{i}^{*}=q \bar{c}^{*}\left(\frac{\alpha+\beta}{\alpha+\beta+\mu}\right)+\frac{\gamma(1-q)}{\alpha+\beta+\mu} a_{i}
\end{gathered}
$$

where $\mu \equiv \gamma \theta(1-q)=\beta \delta \theta(1-q)$. For the cases where $\theta=0$ and/or $q=1$ the equilibrium values for $c_{i}^{*}, e_{i}^{*}$ and $\bar{c}^{*}$ are still given by (7), (8) and (10), respectively. But, as argued above, the personal goal $\tilde{c}_{i}$ is an irrelevant and void concept in these cases and therefore one cannot state an equilibrium value for it. Similarily for $\theta=0$ the reference standard $r_{i}^{*}$ is not defined while for $q=1$ it is given by $r_{i}^{*}=\bar{c}^{*}$ (which can be seen also from (11)).

We have to make an additional assumption about the distribution of incomes in order to guarantee that $c_{i}^{*}-\theta q \bar{c}^{*}-\theta(1-q) \tilde{c}_{i}^{*} \geq 0, \forall i$ (otherwise the maximization problem is not well-definded for some individuals). In particular we assume throughout the paper that $a_{i} \geq \frac{\theta q(\alpha+\mu)}{\alpha+\beta(1-\theta q)+\mu} \bar{a} \equiv \tilde{a}, \forall i$, which guarantees that the income distribution is sufficiently compressed. ${ }^{27}$ Note that for cases where there are no exogenous components of the reference standard $(q=0)$ or when the self-enhancing role of comparisons plays no role $(\theta=0)$ we get that $\tilde{a}=0$ and all ability distributions are admitted.

As argued in the paper the answer to the "Minimum Income Question" (cf. section 4.1) would be given (for $\theta>0$ and $q<1$ ) by $c_{i}^{\min }=\theta r_{i}^{*}$. Noting that in equilibrium there is a clear correspondence between the level of ability and income (given by: $a_{i}=\frac{\alpha+\beta+\mu}{\alpha+\mu} c_{i}^{*}-\frac{\beta \theta q}{\alpha+\mu} \bar{c}^{*}$ ) we can write (using (11)): $r_{i}^{*}=\frac{\alpha q}{\alpha+\mu} \bar{c}^{*}+\frac{\gamma(1-q)}{\alpha+\mu} c_{i}^{*}$. And thus: $c_{i}^{\min }=\frac{\theta q \alpha}{\alpha+\gamma \theta(1-q)} \bar{c}^{*}+\frac{\gamma \theta(1-q)}{\alpha+\gamma \theta(1-q)} c_{i}^{*}$ (cf. equation (2)).

Proposition 1: Using (7), (9) and (11) we can derive: $\frac{\partial \tilde{c}_{i}^{*}}{\partial a_{i}}=\frac{\gamma}{\alpha+\beta+\mu}>0, \frac{\partial r_{i}^{*}}{\partial a_{i}}=$ $\frac{\gamma(1-q)}{\alpha+\beta+\mu}>0$ and $\frac{\partial c_{i}^{*}}{\partial a_{i}}=\frac{\alpha+\mu}{\alpha+\beta+\mu}>0$..

Proposition 2: Using (5) we can derive an important property of our model, namely that for $x=\theta, q$ we get: $\frac{\partial \tilde{c}_{i}^{*}}{\partial x}=-\delta \frac{\partial c_{i}^{*}}{\partial x}$. This means that a change in $\theta$ or in $q$ leads (for every individual $i$ ) to a opposing movement in output $c_{i}^{*}$ and goals $\tilde{c}_{i}^{*}$. Using this and the partial derivate of (6):

$$
\begin{aligned}
& \frac{\partial c_{i}^{*}}{\partial \theta}=\frac{\beta}{\alpha+\beta}\left(q \bar{c}^{*}+q \theta \frac{\partial \bar{c}^{*}}{\partial \theta}+(1-q) \tilde{c}_{i}^{*}+(1-q) \theta \frac{\partial \tilde{c}_{i}^{*}}{\partial \theta}\right) \text { we can easily derive: } \\
& \frac{\partial c_{i}^{*}}{\partial \theta}=\frac{\beta}{\alpha+\beta(1+\delta \theta(1-q))}\left(q \theta \frac{\partial \bar{c}^{*}}{\partial \theta}+q \bar{c}^{*}+(1-q) \tilde{c}_{i}^{*}\right)=\frac{\beta}{\alpha+\beta(1+\delta \theta(1-q))}\left(q \theta \frac{\partial \bar{c}^{*}}{\partial \theta}+r_{i}^{*}\right)>0
\end{aligned}
$$
since $\frac{\partial \bar{c}^{*}}{\partial \theta}=\frac{\beta(\alpha q+\beta \delta(1-q))}{(\alpha+\beta(1-\theta q)+\mu)^{2}} \bar{a}>0$ and $r_{i}^{*}>0$. Since $\frac{\partial \tilde{c}_{i}^{*}}{\partial \theta}=-\delta \frac{\partial c_{i}^{*}}{\partial \theta}$ we can also conclude that:

$$
\frac{\partial \tilde{c}_{i}^{*}}{\partial \theta}<0
$$

\footnotetext{
${ }^{27}$ It also guarantees that $\tilde{c}_{i}^{*} \geq 0$ in $(9)$.
} 
Proposition 3: The cut-off ability level $\hat{a}$ for which $\tilde{c}^{*}(\hat{a})=\bar{c}^{*}$ can be calculated by equating (9) with $\bar{c}^{*}$. It comes out as:

$\hat{a}=\frac{\alpha+\beta(1+\delta \theta)}{\beta \delta} \bar{c}^{*}$, where $\bar{c}^{*}$ is given by (10). Thereby $\hat{a} \geq \tilde{a}$ since

$\hat{a}-\tilde{a}=\frac{\alpha^{2}+\alpha \beta(1+2 \delta \theta(1-q))+\beta^{2} \delta \theta(1-q)(1+\delta \theta(1-q))}{\beta \delta(\alpha+\beta(1-q \theta)+\beta \delta \theta(1-q))} \bar{a}>0$.

Using again (5) and (6) we can calculate the impact of a change in $q$ on $\tilde{c}_{i}^{*}$ :

$\frac{\partial \tilde{c}_{i}^{*}}{\partial q}=\frac{\beta \delta \theta}{\alpha+\beta(1+\delta \theta(1-q))}\left(\tilde{c}_{i}^{*}-\bar{c}^{*}-q \frac{\partial \bar{c}^{*}}{\partial q}\right)$. If $\bar{c}^{*}$ were not an endogenous (equilibrium) value, but exogenously given we would get the interesting condition that: $\frac{\partial \tilde{c}_{i}^{*}}{\partial q} \gtrless 0$ for $\tilde{c}_{i}^{*} \gtrless \bar{c}^{*}$. But $\frac{\partial \bar{c}^{*}}{\partial q}=\frac{\beta \theta(\alpha-\beta \delta(1-\theta))}{(\alpha+\beta(1-\theta q)+\mu)^{2}} \bar{a}$ and thus $\frac{\partial \bar{c}^{*}}{\partial q} \gtreqless 0$ for $\alpha \gtreqless \beta \delta(1-\theta)$ or, equivalently, for $\theta \gtreqless 1-\frac{\alpha}{\beta \delta} \equiv \hat{\theta}$. Substituting the relevant optimal values and collecting terms we can derive the following condition: $\frac{\partial \tilde{c}_{i}^{*}}{\partial q} \gtreqless 0$ for $a_{i} \gtreqless \breve{a}$, where

$\breve{a} \equiv \frac{\alpha+\beta+\mu}{\gamma}\left(\frac{\alpha+\beta+\gamma \theta}{\alpha+\beta+\mu}+\frac{\beta \theta q(\alpha-\beta \delta(1-\theta))}{(\alpha+\beta(1-\theta q)+\mu)(\alpha+\mu)}\right) \bar{c}^{*}$.

In order to grasp the intuition behind this result let us look at the individual with ability level $\hat{a}_{\text {old }}$, who had (before the change in $q$ occured) set $\tilde{c}_{\text {old }}^{*}\left(\hat{a}_{\text {old }}\right)=\bar{c}_{\text {old }}^{*}$. For a constant $\bar{c}^{*}$ he would not change his actively chosen component $\tilde{c}^{*}$ and the impact would be zero (as discussed in the paper). But now the change in $q$ will cause a reaction by the other participants that will in the end lead to a change in $\bar{c}^{*}$. Let us assume for the moment that $\frac{\partial \bar{c}^{*}}{\partial q}>0$. By equation (9) we can calculate the optimal goal of the individual with $\hat{a}_{\text {old }}$ as: $\tilde{c}_{\text {new }}^{*}\left(\hat{a}_{\text {old }}\right)=\frac{\alpha+\beta(1+\delta \theta)}{\alpha+\beta+\mu} \bar{c}_{\text {old }}^{*}-\frac{\beta \delta \theta q}{\alpha+\beta+\mu} \bar{c}_{\text {new }}^{*}$ which is smaller than the old goal, given by $\tilde{c}_{\text {old }}^{*}\left(\hat{a}_{\text {old }}\right)=\bar{c}_{\text {old }}^{*}$. This means that the individual will decrease his goal. The intuition behind this result is again straightforward. If both $q$ and $\bar{c}^{*}$ increase (which we have assumed) then the exogenous part of the reference standard $r\left(\hat{a}_{\text {old }}\right)$ increases. The individual (who had $\tilde{c}_{\text {old }}^{*}\left(\hat{a}_{\text {old }}\right)=\bar{c}_{\text {old }}^{*}$ ) will use his coping leeway in order to partly offset this increase in the forced component of $r$ by reducing his private goals, i.e. by $\frac{\partial \tilde{c}^{*}\left(\hat{a}_{\text {old }}\right)}{\partial q}<0$. Now take an individual with an ability level slightly above $\hat{a}_{\text {old }}$. With an exogenous level of $\bar{c}$ this individual would increase her active component $\tilde{c}$ as a reaction to an increase in $q$. But now the parallel increase in $q$ and $\bar{c}^{*}$ will lead to an increase in her reference standard as well (this will hold if his ability level is sufficiently close to $\hat{a}_{\text {old }}$ ). Thus he will also use his coping possibilities to reduce this impact by lowering his active component $\tilde{c}$. Again there exists an ability level, given by $\breve{a}$, for which $\frac{\partial \tilde{c}^{*}(\breve{a})}{\partial q}=0$, but this no longer coincides with $\hat{a}$. For the case where $\frac{\partial \bar{c}^{*}}{\partial q}<0$ we can use an analogous thought experiment to arrive at the conclusion that the individual with $\hat{a}$ will increase his chosen goal $\tilde{c}$ and the same is true for someone with a slightly lower ability level.

The difference $\breve{a}-\hat{a}$ is given by:

$\breve{a}-\hat{a}=\frac{q \theta(\alpha-\beta \delta(1-\theta))(\alpha+\beta+\beta \delta \theta(1-q))}{\delta(\alpha+\beta(1-q \theta)+\beta \delta \theta(1-q))^{2}} \bar{a}$.

Thus for $\alpha>\beta \delta(1-\theta)$ (or, equivalently, for $\theta>\hat{\theta}$ ) we get that $\breve{a}>\hat{a}$, while for $\theta<\hat{\theta}$ we get that $\breve{a}<\hat{a}$. Furthermore one can calculate that for $\theta \gtrless \hat{\theta}$ we have that $\hat{a} \gtrless \bar{a}$, i.e. that the cut-off value $\hat{a}$ is below or above average ability $\bar{a}$, respectively. For the case where $\theta<\hat{\theta}$ one can finally show that there can be situations where 
$\breve{a}<\tilde{a}$, i.e. constellations where all individuals (with admitted ability levels $a_{i} \geq \tilde{a}$ ) will react to an increase in $q$ by increasing their actively chosen components $\tilde{c}_{i}$. This situation is not possible in the case where $\theta>\hat{\theta}$, since there we have that $\breve{a}>\hat{a}>\bar{a}$ (see above), while at the same time $\tilde{a} \leq \bar{a}$.

Finally it can be shown that the impact of a change in $q$ on the total reference group $r_{i}^{*}$ depends on the same cut-off value $\breve{a}$, i.e. $\frac{\partial r_{i}^{*}}{\partial q} \gtreqless$ for $a_{i} \gtreqless \breve{a}$. Summarizing we thus get that:

$\frac{\partial \widetilde{c}_{i}^{*}}{\partial q}<0, \frac{\partial r_{i}^{*}}{\partial q}<0$ (and by the result from (5) $\frac{\partial c_{i}^{*}}{\partial q}>0$ ) for $a_{i}<\breve{a}$. Conversely $\frac{\partial \tilde{c}_{i}^{*}}{\partial q}>0, \frac{\partial r_{i}^{*}}{\partial q}>0\left(\right.$ and $\left.\frac{\partial c_{i}^{*}}{\partial q}<0\right)$ for $a_{i}>\breve{a}$. In general (i.e. except in the case where $\breve{a}<\tilde{a}$ ) we will thus observe that some (low-ability) individuals will reduce their goals as a reaction to an increase in $q$, while high-ability individuals will increase their goals.

\section{Appendix B-Data Description}

In the empirical section 3.2.2. we use data from the International Social Survey Programme (ISSP), that were collected in 1992 on the topic of "social inequality" in 18 countries. Thereby the number of participants in the survey varied between 749 (Sweden) and 2297 (West Germany). For our analysis we make use of two questions, one about the subjective social class (SSC; V73 in ISSP) and the other about family income (V116 in ISSP). The first question reads as: "In our society there are groups which tend to be towards the top and groups which tend to be towards the bottom. Below is a scale that runs from top to bottom. Where would you put yourself in this scale?" (for Austria and Germany the wording was slightly different). Our purpose in this section is to contrast people's self assessment of their position in the income distribution and the objective position in the income distribution and thus we have to transform these measures into comparable units.

Since there are 10 categories for the SSC-question, running from 1 (Top) to 10 (Bottom) we choose to transform the data into decile measures. Someone answering, e.g., the SSC question by stating "1" (and thus assessing his position as being top) is classified as belonging to the highest (the tenth) "subjective-social-class-decile" and is thus coded as " 10 ", while someone stating " 2 " is put into the ninth SSC-decile etc. (i.e., we simply turn the ISSP codification upside down).

The transformation of the family income data requires some additional data manipulation, which is somewhat complicated since we only have data in categoryform $^{28}$, where the categories are often chosen in a somewhat arbitrary and unevenly distributed fashion. Our procedure of transforming the category-data into decileranks is shortly explained in the following. Denote by $y_{i}$ the income of household $i$ in some country and by $F\left(y_{i}\right)$ the cumulative distribution function. This information,

\footnotetext{
${ }^{28}$ Although there is a variable included (V115) indicating the family incomes directly, this is only available for a limited number of countries, including, e.g., only 3 OECD countries.
} 
however, is not observed in our data sample. Rather we have (for each country) a number $j=1, \ldots, J$ of income brackets, where we associate the $j$ 'th income bracket by the upper limit $b_{j}$ and where (for most countries) $b_{0}=0$ and $b_{J}=\infty .{ }^{29} \mathrm{~A}$ household with income $y_{i}$ will then be counted in the $j$ 'th bracket if $b_{j-1}<y_{i}<b_{j}$. Denote by $g(j)$ the percentage (or frequency) of households belonging to the $j$ 'th income bracket and by $G(j)$ the corresponding cumulative distribution function, i.e., $G(j)=\sum_{k=1}^{j} g(k)$. We transform this into decile ranks by assigning a value of "1" to the brackets with $0<G(j)<0.1$, a value of "2" to the brackets with $0.1<G(j)<0.2$, etc.

\footnotetext{
${ }^{29}$ I.e. the highest bracket is normally stated as " $b_{J-1}$ or above", while the lowest is given as " 0 to $b_{1} "$. (see also the example below).
} 


\section{References}

Adams, J. S. (1965), "Inequity in Social Exchange”, in: Leonhard Berkowitz (ed.), Advances in Experimental Psychology 2, New York: Academic Press, 267-299.

Affleck, G. and H. Tennen (1991), „Social Comparison and Coping With Major Medical Problems", in: Suls, J. and T. A. Wills (eds.), Social Comparison: Contemporary Theory and Research, New Jersey: Lawrence Erlbaum Associates, Inc., Publishers, 237-260.

Akerlof, G. A. (1997), „Social Distance and Social Decisions“, Econometrica, 65(5), 10051027.

Akerlof, G. A. and Yellen, J. L. (1990): "The Fair Wage- Effort Hypothesis and Unemployment", Quarterly Journal of Economics, 105(2), 255-283.

Amiel, Y. (1998), "The Subjective Approach to the Measurement of Income Inequality", in Silber, J. (ed), Income Inequality Measurement: From Theory to Practice, Kluwer, Dewenter.

Argyle, M. (1994), The Psychology of Social Class, London/New York: Routledge.

Bandura, A. (1986), Social foundations of thought and action: A social cognitive theory, Englewood Cliffs, NJ: Prentince-Hall.

Bewley, T. (1995), “A Depressed Labor Market as Explained by Participants”, American Economic Review, 85(2), 250-54.

Blanchflower and Oswald (1992), "Entrepreneurship, Happiness and Supernormal Returns: Evidence from Britain and the US", NBER Working Paper No. 4228.

Boskin M. J. and E. Sheshinski (1978), „Optimal Redistributive Taxation when Individual Welfare Depends on Relative Income“, Quarterly Journal of Economics, 92(4), 589-601.

Brown, J. D. and Dutton, K. A. (1995): "Truth and Consequences: The Cost and benefits of accurate self-knowledge", Personality and Social Psychology Bulletin, 21(2), 1288-1296.

Campbell, J. D. (1986): "Similarity and uniqueness: The effects of attribute type, relevance, and individual differences in self-esteem and depression", Journal of Personality and Social Psychology, 50, 281-294.

Campbell, C. M. and Kamlani, K. S. (1997), The Reasons for Wage Rigidity: Evidence from a Survey of Firms", The Quarterly Journal of Economics, 112, 759-789.

Campbell, J. Y. and J. H. Cochrane (1999), "By Force of Habit: A Consumption-Based Explanation of Aggregate Stock Market Behavior", Journal of Political Economy, 107(2), 205-51.

Carroll, C. D., J. Overland and D. N. Weil (1997), „Comparison Utility in a Growth Model“, Journal of Economic Growth, 2(4), 339-367.

Carroll, C. D. (1998), “Why Do the Rich Save So Much?”, NBER Working Paper No.: 6459.

Clark, A. E. and A. J. Oswald (1998), "Comparison-Concave Utility and Following Behaviour in Social and Economic Settings“", Journal of Public Economics, 70(1), 133155.

Clark, A. E. and A. J. Oswald (1996), „Satisfaction and Comparison Income“, Journal of Public Economics, 61(3), 359-381.

Clark, A. E. and A. J. Oswald and P. B. Warr (1994), " Is Job Satisfaction U-Shaped in Age?", CEPREMAP Discussion Paper: 9407.

Colasanto, D., Kapteyn, A. and J. van der Gaag (1984), "Two subjective definitions of poverty: Results from the Wisconsin basic needs study", The Journal of Human Resources, 19(1), 127-138.

Cole, H. L., George J. M. and A. Postlewaite (1992), „Social Norms, Savings Behavior, and Growth“, Journal of Political Economy 100(6), 1092-1125.

Cooper, B. and C. Garcia-Penalosa (1999), "Status Effects and Negative Utility Growth", Nuffield College Discussion paper No. 150. 
Corneo, G. and O. Jeanne (1998), „Social Organization, Status, and Savings Behavior“, Journal of Public Economics, 70(1), 37-51.

Danzinger, S., J. van der Graag and M.K. Taussig (1984), "The direct measurement of welfare levels: How much does it cost to make ends meet?", Review of Economics and Statistics, 66, 500-505.

De Vos, K. and T.I. Garner (1991), "An evaluation of subjective poverty definitions: Comparing results from the US and the Netherlands", Review of Income and Wealth, 37(3), 267-285.

Diener E. and Fujita, F. (1997), "Social Comparison and Subjective Well-Being", in Health, Coping and Well-Being, edited by B. P. Buunk and R. Gibbons, Mahwah, NJ: Erlbaum.

Diener, E. Suh, E., \& Lucas, R., \& Smith, H. (1999), "Subjective well-being: Three decades of progress", Psychological Bulletin, 125, 276-302.

Di Tella, R., R. MacCulloch and A. Oswald (2000), „Preferences over Inflation and Unemployment: Evidence from Surveys of Happiness", forthcoming American Economic Review.

Duesenberry, J. S. (1949), Income, Saving and the Theory of Consumer Behavior, Cambridge, MA: Harvard University Press.

Easterlin, R. A. (1981), „Why Isn't the Whole World Developed?“, Journal of Economic History, 41(1), 1-19.

Easterlin, R. A. (1995), "Will Raising the Incomes of All Increase the Happiness of All?", Journal of Economic Behavior and Organization, 27(1), 35-47.

Falk, A. and U. Fischbacher (1998), „A Theory of Reciprocity“, Working Paper Series No. 6, Institute for Empirical Economic Research, University of Zurich.

Fehr, E. and K. M. Schmidt (1999), „A Theory of Fairness, Competition, and Cooperation“, Quarterly Journal of Economics, 114(3), 817-68.

Fehr, E. and A. Falk (1999), "Wage Rigidity in a Competitive Incomplete Contract Market", Journal of Political Economy, 107(1), 106-34.

Festinger, L (1954), "A theory of social comparison processes", Human Relations, 7, 117140.

Frank (1984), "Interdependent Preferences and the Competitive Wage Structure", Rand Journal of Economics, 15(4), 510-20.

Frank, R. H. (1985), Choosing the Right Pond. Human Behavior and the Quest for Status, Oxford University Press: New York and Oxford.

Frank, R. H. (1999), Luxury Fever. Why Money Fails to Satisfy in an Era of Excess, The Free Press: New York.

Frank, R. H. and P. J. Cook (1995), „The Winner-Take-All Society: How more and more Americans compete for ever fewer and bigger prizes, encouraging economic waste, income inequality, and an impoverished cultural life", New York; London and Toronto: Simon and Schuster, Free Press.

Frey, B.S. and A. Stutzer (2000), „Happiness, Economy and Institutions“, forthcoming: Economic Journal.

Goedhart, T., Halberstadt, V., Kapteyn , A. and B. van Praag (1977), "The poverty line: Concept and measurement", The Journal of Human Resources, 12(4), 503-520.

Graham, C. and S. Pettinato (1999), "Assessing Hardship and Happiness: Trends in Mobility and Expectations in the New Market Economies", CSED Working Paper No. 7.

Hagenaars, A.J.M. and B. van Praag (1985), "A synthesis of poverty line definitions", Review of Income and Wealth, 31(2), 139-153.

Hof, F. X. (1999), "Relative Consumption and Endogenous Labor Supply in the Ramsey Model: Do Status-Conscious People Work Too Much?“, Working Paper 99/02, Institute of Economics, University of Technology Vienna.

James, W. (1952) (1891), The Principles of Psychology, Chicago: Britannica. 
Johansson-Stenman, O., F. Carlsson and D. Daruvala (1999), "Measuring Hypothetical Grandparents' Preferences for Equality and Status", Working paper, Göteborg University.

Kilpatrick, R.W. (1973), "The income elasticity of the poverty line", The Review of Economics and Statistics, 55(3), 327-332.

Klein, S. M. and Maher, J. R. (1966), "Education Level and Satisfaction with Pay", Personnel Psychology 19, 195-208.

Knell, M. (1999), "Social Comparisons, Inequality, and Growth", Journal of Institutional and Theroetical Economics, 112(4), 664-695.

Kruglanski, A. W. and O. Mayseless (1990). "Classic and current social comparison research: Expanding the perspective", Psychological Bulletin, 108, 195-208.

Layard, R (1980), „Human Satisfaction and Public Policy“, Economic Journal, 90(363), 737750.

Loewenstein, G. F., L. Thompson and M. H. Bazerman (1989), „Social Utility and Decision Making in Intertemporal Contexts“, Journal of Personality and Social Psychology, 57(3), 426-441.

Maccoby, E. E. and C. N. Jacklin (1974), The psychology of sex differences, Stanford, CA: Stanford University Press.

Major, B., M. Testa and W. H. Bylsma (1991), "Responses to Upward and Downward Social Comparisons: The Impact of Esteem-relevance and Perceived Control", in: Suls, J. and T. A. Wills (eds.), Social Comparison: Contemporary Theory and Research, New Jersey: Lawrence Erlbaum Associates, Inc., Publishers, 237-260.

Marks, G. (1984): “Thinking one's are unique and one's opinions are common”, Personality and Social Psychology, 45, 384-393.

Marsh, H. W. (1987): "The big-fish-little-pond effect on academic self-concept", Journal of Educational Psychology, 79, 280-295.

Merton, R. and A. Kitt (1950), „Contributions to the Theory of Reference Group Behavior“, in: R. Merton and P. Lazarsfeld (eds.), Continuities in Social Research: Studies in the Scope and Method of Reference Group Behavior, The Free Press: Glencoe, Ill.

Neumark and Postlewaite (1998), "Relative Income Concerns and the Rise in Married Women's Employment", Journal of Public Economics, 70(1), 157-83.

Okun, A. M. (1975), Equality and Efficiency. The Big Tradeoff, The Brookings Institution.

Oswald, A. (1997), "Happiness and Economic Performance", Economic Journal, 107 (445), $1815-1831$.

Rainwater, L. (1974), What Money Buys, New York: Basic Books.

Roberti, P. (1980), „Counting the Poor: A Review of the Situation Existing in Six Industrialized Nations“, pp. 306-340 in: A. B. Atkinson (ed.), Wealth, Income and Inequality, New York: Oxford University Press.

Schor, J. (1992), The Overworked American. The Unexpected Decline of Leisure, New York: Basic Books.

Schor, J. (1998), The Overspent American. Upscaling, Downshifting, and the New Consumer, New York: Basic Books.

Sen, A. (1983), „Poor, Relatively Speaking“, Oxford Economic Papers, 35(2), 153-169.

Seta, J. (1982): "The impact of comparison processes on coactors' task performance", Journal of Personality and Social Psychology, 42, 281-291.

Stanovnik, T. (1992), "Perception of poverty and income satisfaction. An empirical analysis of Slovene households", Journal of Economic Psychology, 13(1), 57-69.

Taylor, S. E., J. V. Wood and R. R. Lichtman (1983): "It could be worse: Selective evaluations as a response to victimization", Journal of Social Issues, 39, 19-40.

van Praag, B.M.S. (1993), „The Relativity of the Welfare Concept", in: Nussbaum, M. and A. Sen (eds.), The quality of life, World Institute for Development Economics Research 
Studies in Development Economics. Oxford, New York, Toronto and Melbourne: Oxford University ress, Clarendon Press, 1993, 362-85.

van Praag, B.M.S., T. Goedhart and A. Kapteyn (1980), "The poverty line - A pilot survey in Europe", The Review of Economics and Statistics, 62(3), 461-465.

Veenhoven, R. (2000), "Freedom and Happiness. A Comparative Study in 46 Nations in the Early 1990's", mimeo, Rotterdam University.

Warr, P. (1992), “Age and Occupational Well Being”, Psychology and Aging 7, 37-45.

Wills, T. A. (1981), "Downward Comparison principles in social psychology", Psychological Bulletin 90, 245-271.

Woittiez, Isolde and Arie Kapteyn (1998), ,Social Interactions and Habit Formation in a Model of Female Labour Supply“, Journal of Public Economics, 70(2), 185-205.

Wood, J. V. and K. L. Taylor (1991), "Serving Self-Relevant Goals Through Social Comparison", in: Suls, J. and T. A. Wills (eds.), Social Comparison: Contemporary Theory and Research, New Jersey: Lawrence Erlbaum Associates, Inc., Publishers, 23-49.

Zuckerman, M. (1979): "Attribution of success and failure revisited, or: The motivational bias is alive and well in attribution theory", Journal of Personality 47, 245-287. 
Table 1 - Answers to the question: Do you try harder if you set yourself high goals? percent

$1=$ do not agree at all $\quad 2.75$

$2=$ do rather not agree $\quad 7.06$

$3=$ do not know $\quad 10.98$

$4=$ rather agree $\quad 43.92$

$5=$ totally agree $\quad 35.29$

mean (std. dev.) $4.02(.99)$

Numbers of observation

255 
Table 2 - Ordered Probit Estimates of Aspired Degree on the Final University Examination

\begin{tabular}{|c|c|c|c|}
\hline & Model 1 & Model 2 & Model 3 \\
\hline High School Degree (ability) & $\begin{array}{l}.737 * * \\
(.000)\end{array}$ & $\begin{array}{c}.803 * * \\
(.000)\end{array}$ & $\begin{array}{c}.831 * * \\
(.000)\end{array}$ \\
\hline Sex & & $\begin{array}{c}-.401 * * \\
(.006)\end{array}$ & $\begin{array}{c}-.438 * * \\
(.003)\end{array}$ \\
\hline Age & & $\begin{array}{l}-.003 \\
(.889)\end{array}$ & $\begin{array}{c}.003 \\
(.898)\end{array}$ \\
\hline Technical Department & & $\begin{array}{c}-.469 * * \\
(.002)\end{array}$ & $\begin{array}{c}-.486 * * \\
(.001)\end{array}$ \\
\hline Native & & $\begin{array}{l}-.110 \\
(.614)\end{array}$ & $\begin{array}{l}-.181 \\
(.419)\end{array}$ \\
\hline Community Size & & $\begin{array}{l}-.062 \\
(.418)\end{array}$ & $\begin{array}{l}-.086 \\
(.272)\end{array}$ \\
\hline Money Available & & $\begin{array}{c}.000 \\
(.353)\end{array}$ & $\begin{array}{c}.000 \\
(.321)\end{array}$ \\
\hline Working Hours & & $\begin{array}{c}.004 \\
(.726)\end{array}$ & $\begin{array}{c}.002 \\
(.805)\end{array}$ \\
\hline Wealthy Family Background & & & $\begin{array}{c}.014 \\
(.783)\end{array}$ \\
\hline Well Educated Parents & & & $\begin{array}{l}-.103 \\
(.079)\end{array}$ \\
\hline Good Own Education & & & $\begin{array}{c}.007 \\
(.943)\end{array}$ \\
\hline Ambitions & & & $\begin{array}{c}.169 \\
(.041)^{*}\end{array}$ \\
\hline Natural Talents & & & $\begin{array}{c}.047 \\
(.453)\end{array}$ \\
\hline Hard Work & & & $\begin{array}{l}-.112 \\
(.070)\end{array}$ \\
\hline Knowing the Right People & & & $\begin{array}{l}-.026 \\
(.686)\end{array}$ \\
\hline Political Connections & & & $\begin{array}{c}.047 \\
(.390) \\
\end{array}$ \\
\hline $\mathrm{N}$ & 255 & 249 & 249 \\
\hline Log likelihood & -542.402 & -519.488 & -514.611 \\
\hline Prob $>$ chi 2 & .000 & .000 & .000 \\
\hline
\end{tabular}

\footnotetext{
${ }^{\dagger}$ Note: Significance levels using two-tailed tests: $*=$ significant at the 5-percent level; $* *=$ significant at the 1percent level; Sex: 1=female, 0=male; Technical Department: 1=yes, 0=no; Native: 1=swiss, 0=not Swiss; Community size1=up to 2.000 inhabitants, $2=2.000$ to $10^{\prime} 000$ inhabitants, $3=10.000$ to 100.000 inhabitants, 4=more than 100.000 inhabitants; Money available: Money for living net rent (monthly); Working hours: Hours worked net hours for study (weekly); The additional variables in model 3 are taken from the GSSB-survey. The question was: "Please indicate for all following reasons, how important they are for getting ahead." Answers are coded in the following way: 1=not at all important, 2=not very important, 3=don't know, 4=important, 5=pretty important, $6=$ very important. In model 2 and 3 the number of observations is smaller due to missing answers.
} 
Table 3 - Happiness and Social Perception

\begin{tabular}{|c|c|c|c|c|}
\hline Country & $\begin{array}{c}\text { HAPPY } \\
\text { (scale 1-4) }\end{array}$ & $\begin{array}{c}\text { MEANSSC } \\
\text { (scale 1-10) }\end{array}$ & $\begin{array}{c}\text { OVER } \\
\text { (percent) }\end{array}$ & $\begin{array}{l}\text { UNDER } \\
\text { (percent) }\end{array}$ \\
\hline Australia & 3.30 & 5.88 & & \\
\hline Austria & 3.20 & 5.77 & 42.78 & 44.48 \\
\hline Bulgaria & 2.33 & 3.84 & & \\
\hline Canada & 3.05 & 5.83 & 36.23 & 51.77 \\
\hline Czechoslovakia (former) & 2.69 & 4.69 & & \\
\hline Germany-East (former) & 2.96 & 4.71 & & \\
\hline Germany-West (former) & 3.04 & 5.72 & 41.51 & 47.74 \\
\hline Hungary & 2.72 & 3.92 & & \\
\hline Italy & 2.98 & 4.93 & 30.24 & 56.90 \\
\hline New Zealand & 3.18 & 5.99 & 35.83 & 50.63 \\
\hline Norway & 3.23 & 5.85 & 39.03 & 46.72 \\
\hline Philippines & 3.08 & 4.36 & & \\
\hline Poland & 2.97 & 4.32 & 23.39 & 66.42 \\
\hline Russia & 2.53 & 4.40 & 26.80 & 62.64 \\
\hline Slovenia & 2.62 & 4.77 & 29.12 & 60.86 \\
\hline Sweden & 3.36 & 5.70 & & \\
\hline United Kingdom & 3.28 & 5.34 & 30.71 & 55.74 \\
\hline United States & 3.28 & 5.54 & 39.26 & 48.99 \\
\hline Correlation with & 1.00 & 0.79 & 0.61 & -0.69 \\
\hline $\begin{array}{l}\text { HAPPY } \\
\text { Spearman's rho } \\
\text { with } H A P P Y\end{array}$ & $\begin{array}{c}1.00 \\
(0.00)\end{array}$ & $\begin{array}{c}0.71 * * * \\
(0.001)\end{array}$ & $\begin{array}{l}0.66^{* *} \\
(0.028)\end{array}$ & $\begin{array}{c}-0.69 * * \\
(0.019)\end{array}$ \\
\hline
\end{tabular}

Source: See Appendix B. 
Figure 1 - The Reference Standard Dependent on the Ability Level

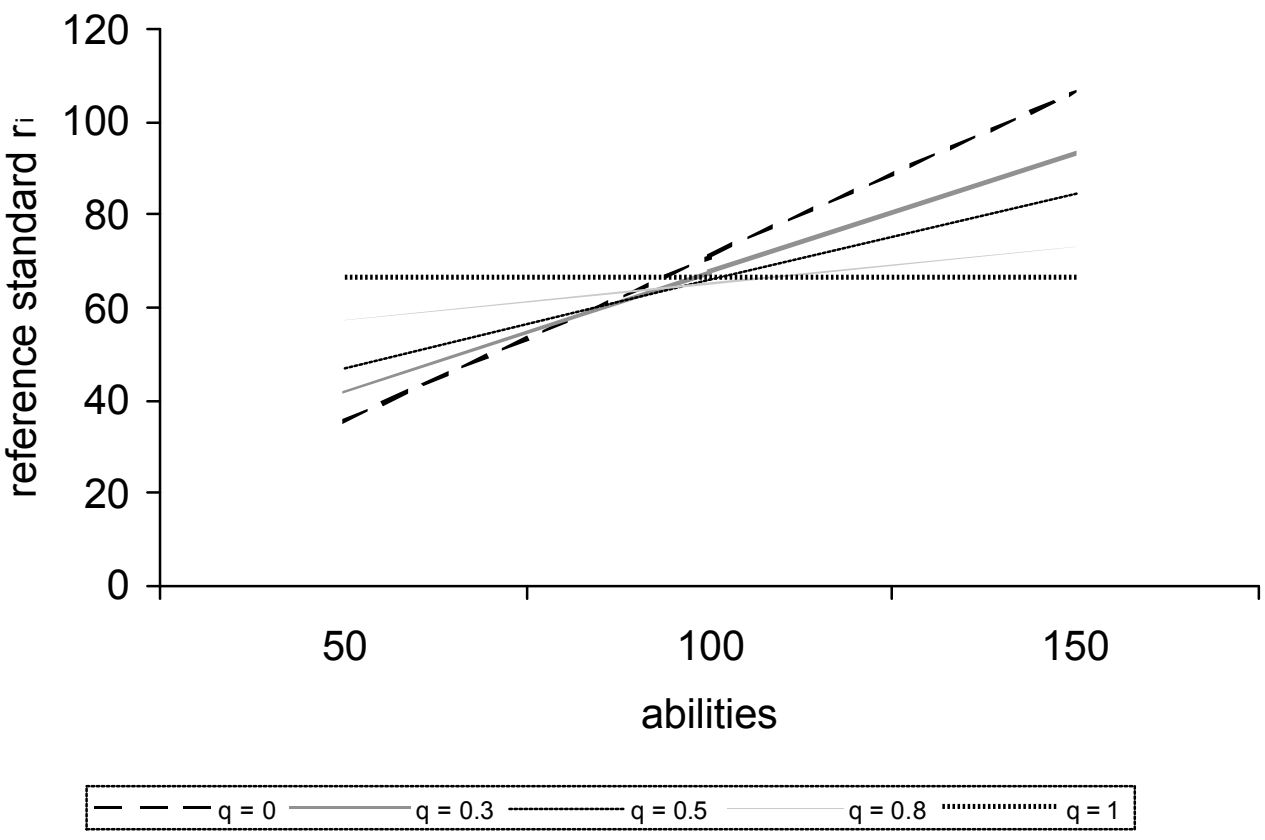

Parameterization: $\alpha=0.5, \beta=0.5, \delta=0.5, \theta=0.5, \gamma=0.8, \overline{\mathrm{a}}=100$ 
Figure 2 - Subjective vs. Objective Social Class
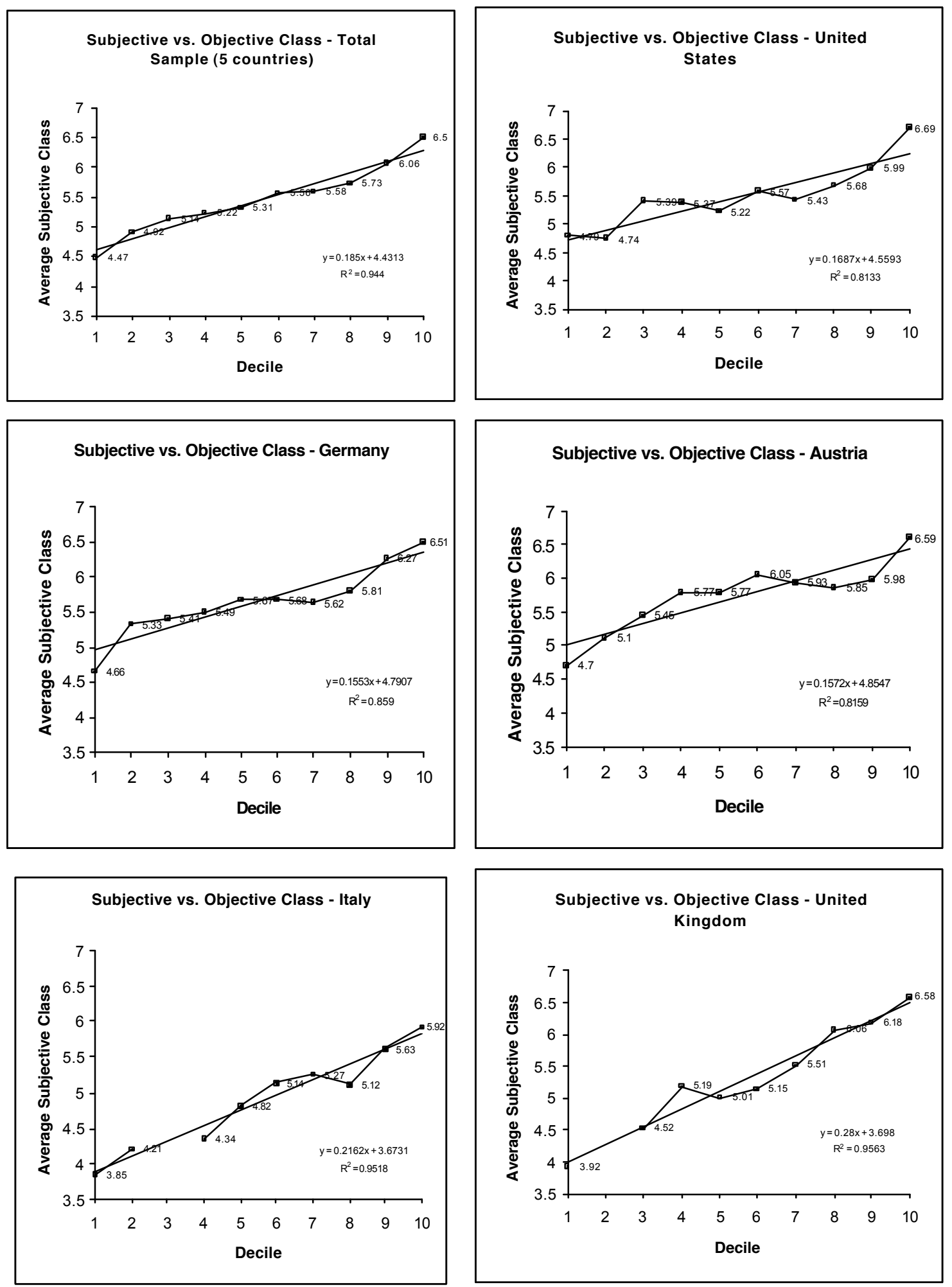

Source: See Appendix B. The straight lines are regression lines, which were estimated by OLS. 
Figure 3 - Subjective vs. Objective Perception of Income Total Sample (5 countries)

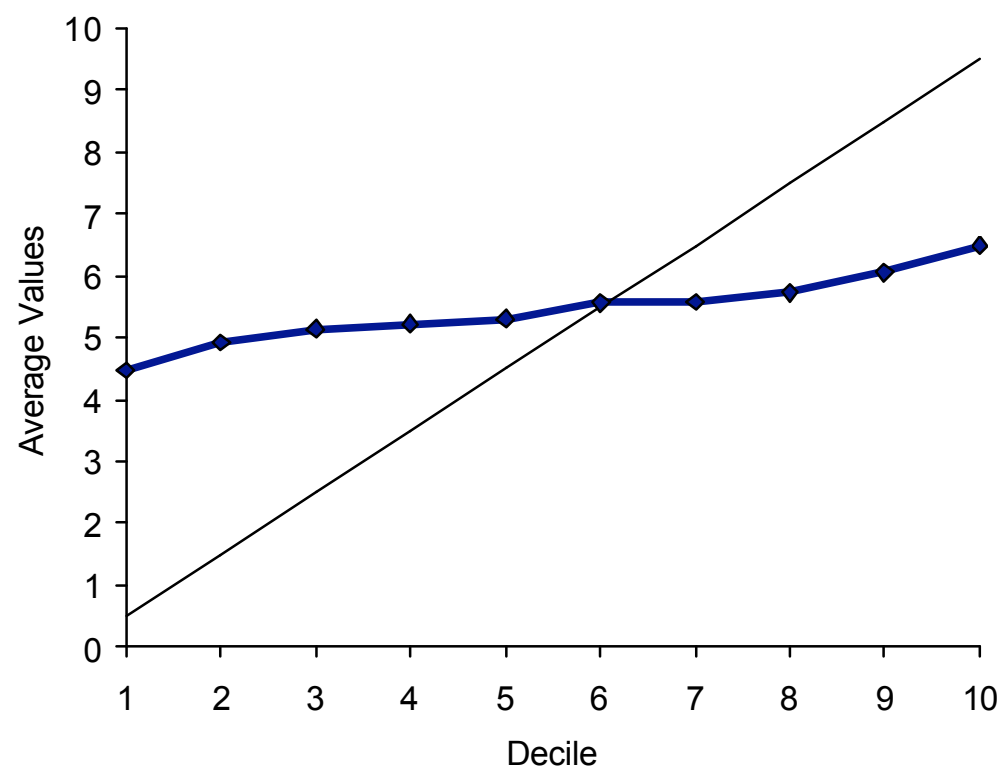

$\sim$ Subjective Perception -Objective Perception

Source: See Appendix B. The "Subjective Perception" curve is the same as appears in the upper left panel of Figure 2, only with a different scaling. 